\title{
A Smart Multifunctional Nanoparticle for Enhanced Near-Infrared Image-Guided Photothermal Therapy Against Gastric Cancer
}

\author{
Jun Shao $\mathbb{D}^{1, *}$ \\ Rongpu Liang ${ }^{1} *$ \\ Dongbing Ding ${ }^{1} *$ \\ Xiaoming Zheng' \\ Xudong Zhu' \\ Shengxue $\mathrm{Hu}^{2}$ \\ Hongbo Wei' \\ Bo Wei ${ }^{1}$
}

'Department of Gastrointestinal Surgery, The Third Affiliated Hospital of Sun Yatsen University, Guangzhou, 510630,

People's Republic of China; ${ }^{2}$ College of Biological Science and Engineering,

Fuzhou University, Fujian, 350108,

People's Republic of China

*These authors contributed equally to this work
Correspondence: Hongbo Wei; Bo Wei Department of Gastrointestinal Surgery, The Third Affiliated Hospital of Sun Yatsen University, Guangzhou, 510630,

People's Republic of China

Tel +86-20-85252228

Email weihb@mail.sysu.edu.cn;

weibo3@mail.sysu.edu.cn
Background: Surgery is considered to be a potentially curative approach for gastric cancer. However, most cases are diagnosed at a very advanced stage for the lack of typical symptoms in the initial stage, which makes it difficult to completely surgical resect of tumors. Early diagnosis and precise personalized intervention are urgent issues to be solved for improving the prognosis of gastric cancer. Herein, we developed an RGD-modified ROS-responsive multifunctional nanosystem for near-infrared (NIR) imaging and photothermal therapy (PTT) against gastric cancer.

Methods: Firstly, the amphiphilic polymer was synthesized by bromination reaction and nucleophilic substitution reaction of carboxymethyl chitosan (CMCh) and 4-hydroxymethyl-pinacol phenylborate (BAPE). Then, it was used to encapsulate indocyanine green (ICG) and modified with RGD to form a smart multifunctional nanoparticle targeted to gastric cancer (CMCh-BAPERGD@ICG). The characteristics were determined, and the targeting capacity and biosafety were evaluated both in vitro and in vivo. Furthermore, CMCh-BAPE-RGD@ICG mediated photothermal therapy (PTT) effect was studied using gastric cancer cells (SGC7901) and SGC7901 tumor model. Results: The nanoparticle exhibited suitable size $(\approx 120 \mathrm{~nm})$, improved aqueous stability, ROSresponsive drug release, excellent photothermal conversion efficiency, enhanced cellular uptake, and targeting capacity to tumors. Remarkably, in vivo studies suggested that CMCh-BAPE-RGD@ICG could accurately illustrate the location and margin of the SGC7901 tumor through NIR imaging in comparison with non-targeted nanoparticles. Moreover, the antitumor activity of CMCh-BAPERGD@ICG-mediated PTT could effectively suppress tumor growth by inducing necrosis and apoptosis in cancer cells. Additionally, CMCh-BAPE-RGD@ICG demonstrated excellent biosafety both in vitro and in vivo.

Conclusion: Overall, our study provides a biocompatible theranostic nanoparticle with enhanced tumor-targeting ability and accumulation to realize NIR image-guided PTT in gastric cancer.

Keywords: gastric cancer, nanoparticle, indocyanine green, near-infrared imaging, photothermal therapy

\section{Introduction}

Gastric cancer is the second leading cause of cancer-related death and approximately 1,033,000 new cases are diagnosed and 783,000 deaths are estimated worldwide in 2018 according to GLOBACAN statistics. ${ }^{1}$ Surgery, radiotherapy, and chemotherapy are the conventional treatments for gastric cancer. ${ }^{2-4}$ Although these therapeutic methods have improved the survival rate to some extent, the great trauma of surgery, the non-targeted ability and toxic side effects of radiotherapy and chemotherapy have 
seriously affected the quality of life of patients. Furthermore, since there is no or little typical symptoms in the initial stage, ${ }^{5}$ the majority of patients with gastric cancer are diagnosed middle and advanced tumors (at stage II or III). Complete surgical resection of tumors in these cases remains extremely challenging. And for the lack of haptic feedback, surgeons may also have misjudgments about small lesions during laparoscopic surgery of gastric cancer. Therefore, early diagnosis and precise personalized intervention are urgent issues to be solved for improving the prognosis of patients with gastric cancer.

Photothermal therapy, which destroys tumor cells through heat produced by photothermal agents, has become a promising alternative strategy over the past few decades. ${ }^{6-9}$ Meanwhile, nanoscale drug delivery systems (NDDS) combining imaging and therapy is increasingly favored by researchers. ${ }^{10-13}$ The method of administration combining photothermal agents and nanomaterials could not only demonstrate the specific location of the lesion but also achieve more precise personalized intervention of the tumor. For a satisfied image-guided therapy, the prerequisites is to design a biocompatible NDDS with specific tumortargeting ability and a multifunctional theranostic agent that demonstrates imaging and therapeutic functions. ${ }^{14}$

To date, many theranostic agents including metal nanostructures, ${ }^{15}$ near-infrared (NIR) dyes, ${ }^{16}$ carbon nanomaterials, ${ }^{17}$ polymeric nanoparticles, ${ }^{13}$ and many others have been widely explored for imaging-guided treatment for cancer, among which indocyanine green (ICG) is the only approved NIR dye for clinical application. Since tissues are relatively transparent under NIR illumination, ICG displays several obvious advantages, including minimal background fluorescence interference, deeper tissue penetration, and realtime monitoring during the operation. ${ }^{18,19}$ Additionally, ICG is also a photosensitizer with excellent photothermal conversion efficiency when exposed to single wavelength NIR light. ${ }^{14,20}$ These attractive features indicate that ICG could be a promising dye for tumor imaging and PTT. ${ }^{11,21}$ So far, ICG has been used for the determination of liver function and liver blood flow, ${ }^{22}$ cardiac output, ${ }^{23}$ and ophthalmic angiography. $^{24}$ Nevertheless, several intrinsic drawbacks limit its ideal application in clinical practice. Self-aggregation and instability in solution lead to fluorescence quenching. Nonspecific binding to plasma proteins and rapid elimination through hepatobiliary excretion result in a half-life of only 2 4 min. Moreover, the nontargeting ability to tumor limits its application in tumor diagnosis and treatment. ${ }^{19}$ Several attempts have been made to overcome these challenges, such as modification of ICG with ligands to improve targeting ability, ${ }^{25}$ encapsulation of ICG into nanocarriers to provide increased efficacy. ${ }^{14,19,26}$ Compared with the former which usually cannot enhance the stability of ICG, the latter (NDDS) seems to be a more hopeful strategy to enhance its stability, prolong circulation and improve targeting ability.

NDDS has several advantages over the traditional pattern of drug administration. ${ }^{27-29}$ First, the encapsulated ICG by nanomaterials could be rescued from nonspecific binding to plasma proteins, thus increasing its half-life in vivo. Second, the passive targeting delivery, which is associated with enhanced permeability and retention (EPR) effect and transcytosis (perhaps with other unknown mechanisms), makes it possible for nanomaterials within a specific size range to selectively pass through and retain in the tumor. ${ }^{30-32}$ Third, the surface of nanomaterials could be modified with specific ligands to achieve active targeting delivery. For instance, specific cell surface receptors, such as transferrin or folate receptors, are overexpressed in tumor cells such as malignant glioma and breast cancer. ${ }^{33}$ Nanomaterials modified with peptides, aptamers, and monoclonal antibodies ${ }^{30,33}$ can increase specific cellular uptake through receptor-mediated endocytosis (RME) effect, thus resulting in the accumulation of drugs in the target cells and increasing the payload of drug delivery. Integrins are a family of transmembrane receptors capable of mediating bidirectional signaling through the membrane, including invasion, migration, survival, and proliferation. $^{34,35}$ Integrin $\alpha_{\mathrm{v}} \beta_{3}$, which is overexpressed in gastric cancer, may be helpful in the routine classification of gastric cancer subtypes and services as a novel putative prognostic biomarker. ${ }^{36}$ Arg-Gly-Asp (RGD) is a tripeptide sequence that can specifically recognize and bind integrin $\alpha_{v} \beta_{3}$. In the past few years, the RGD family has been developed into a variety of subtypes, such as RGD straight-chain, internalizing-RGD, and cyclic RGD. ${ }^{14,37}$ Shan et al ${ }^{38}$ prepared an RGD-modified hepatitis $\mathrm{B}$ core protein virus-like particle (HBc VLP) and it displayed high-efficiency endocytosis in vitro and improved tumor-targeted accumulation in vivo compared with non-targeted particles. Therefore, the functionalization of RGD polypeptides can greatly improve the tumor-targeting ability of nanomaterials.

In practical application, the poor uptake of nanomaterials by targeted cells and incomplete intracellular release limit its curative effect. $^{39}$ To further improve the bioavailability of drugs, the unique microenvironment of tumor tissue, such as low $\mathrm{pH}$, high concentration of glutathione (GSH), high concentration of reactive oxygen species (ROS), etc., has been 
used to design environmentally responsive nano-drug delivery systems, which can target to the tumor site and release the loaded drugs in the targeted tumor cells. ${ }^{10,18,26,29,39,40}$ In this paper, we synthesize a novel ICG-loaded ROS-responsive RGD-modified nanoparticle for simultaneous gastric cancer NIR imaging and PTT (Scheme 1). The amphiphilic block nanoparticle is mainly composed of four parts: carboxymethyl chitosan $(\mathrm{CMCh})$ acts as a hydrophilic shell to realize the water solubility of the complex; benzeneboronic acid pinacol ester (BAPE) forms the hydrophobic end and hydrolyzes under the stimulation of excessive ROS in the tumor site to achieve targeted release of ICG; RGD polypeptides are conjugated on the surface to achieve active targeting ability of the nanosystem; ICG is used as a bifunctional dye to realize NIR imaging and PTT. We investigated the preparation and characterization of nanoparticles. The cellular uptake, cytotoxicity, and photothermal conversion performance were systematically analyzed in vitro. Their NIR imaging and anti-tumor efficiency on tumor-bearing mice (SGC7901 cells) were studied. The outcome of our work may demonstrate a promising way to integrate NIR imaging into PTT of gastric cancer.

\section{Materials and Methods Materials}

Benzeneboronic acid pinacol ester (BAPE), carboxymethyl chitosan $(\mathrm{CMCh})$, phosphorus tribromide $\left(\mathrm{PBr}_{3}\right), \mathrm{Na}_{2} \mathrm{CO}_{3}$, acetonitrile, dichloromethane, 1-ethyl-3-(3-dimethylaminopropyl) carbodiimide hydrochloride (EDC), and N-hydroxysuccinimide (NHS) were purchased from Shanghai Macklin Biochemical Technology Co., Ltd (Shanghai, China). Indocyanine green (ICG) was obtained from Shanghai Ronghe Pharmaceutical Technology Co. Ltd. (Shanghai, China). RGD polypeptide was bought from

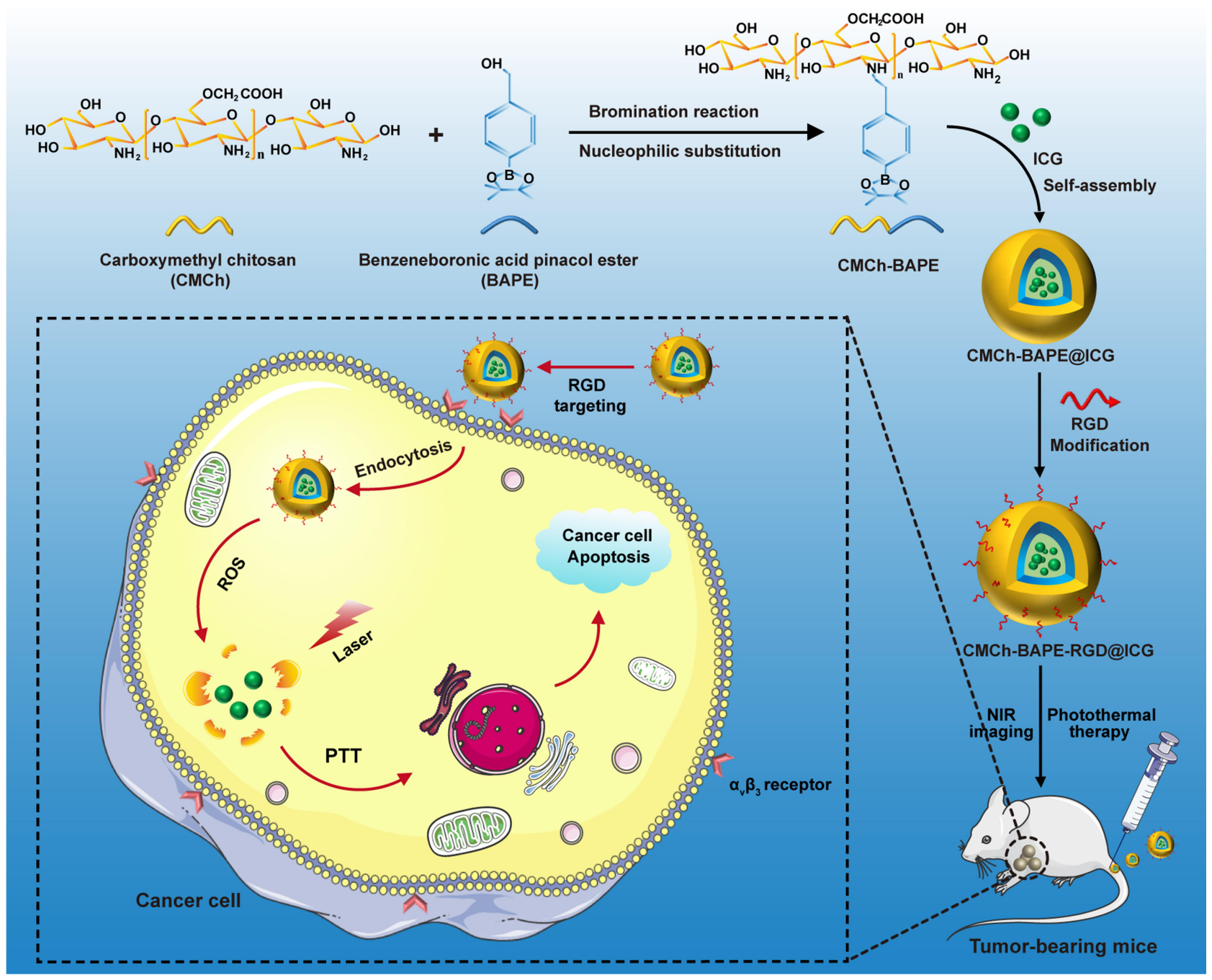

Scheme I Schematic illustration of CMCh-BAPE-RGD@ICG for NIR imaging and photothermal therapy of gastric cancer. 
Shanghai Jier Biochemical Co., Ltd. Cell culture reagents including Dulbecco's modified Eagle's medium (DMEM), RPMI 1640, fetal bovine serum (FBS), trypsin, and antibiotics were all bought from Gibco (Gaithersburg, MD, USA). ROS detection assay kit was bought from Beyotime Biotechnology in China. Cell counting kit-8 (CCK-8) and Live/Dead cell staining kits were obtained from Kaiji Bio-tech Co., Ltd. (Jiangsu, China). Annexin-V/PE Apoptosis Detection Kit was purchased from the BD in America. Mouse fibroblastic cells L929 and human gastric cancer SGC7901 cells were purchased from Beogene Biotechnology Co., Ltd. (Guangzhou, China). All other reagents were of analytical grade unless otherwise noted.

\section{Preparation of CMCh-BAPE-RGD@ICG Nanoparticles \\ Preparation of CMCh-BAPE Nanoparticles}

CMCh-BAPE nanoparticles were prepared as previously reported. ${ }^{41}$ Briefly, $0.46 \mathrm{~g}$ (2 mmol) 4-hydroxymethylpinacol phenylborate (BAPE) was weighed and dissolved in $10 \mathrm{~mL}$ dichloromethane, followed by the addition of $0.1 \mathrm{~mL}$ phosphorus tribromide $\left(\mathrm{PBr}_{3}\right)$. The solution reacted at room temperature for $2 \mathrm{~h}$ under nitrogen atmosphere. Then, a rotary evaporator was applied to remove the organic solvent. Next, the resulting product was dissolved by an appropriate amount of acetonitrile. A 5\% $\mathrm{Na}_{2} \mathrm{CO}_{3}$ solution was used to adjust the $\mathrm{PH}$. Subsequently, $0.52 \mathrm{~g}(1 \mathrm{mmol})$ carboxymethyl chitosan $(\mathrm{CMCh})$ dissolved in pure water was added to the solution. After $48 \mathrm{~h}$ of reaction under the protection of nitrogen gas, the mixed sample was dialyzed for 3 days against pure water in a dialysis sack (MWCO: $3500 \mathrm{Da}$ ) to remove all the impurities. The CMCh-BAPE was lyophilized and stored at $-20^{\circ} \mathrm{C}$.

\section{Preparation of CMCh-BAPE@ICG Nanoparticles}

The loading of ICG to the nanoparticles was based on the self-assembly method. Generally, $10 \mathrm{mg}$ ICG was dissolved in $5 \mathrm{~mL}$ pure water, followed by dropwise added to an aqueous solution containing $50 \mathrm{mg} \mathrm{CMCh}-\mathrm{BAPE}$. The mixture solution was further stirred for $4 \mathrm{~h}$ at room temperature. A dialysis bag (MWCO: $1000 \mathrm{Da}$ ) was used for purifying the nanoparticles for $24 \mathrm{~h}$. The final production (CMChBAPE@ICG) was lyophilized and stored at $-20^{\circ} \mathrm{C}$.

\section{Preparation of CMCh-BAPE-RGD@ICG Nanoparticles}

CMCh-BAPE@ICG (50 mg) was first dissolved in an appropriate amount of pure water, followed by added with $5.6 \mathrm{mg}$ EDC and $8.4 \mathrm{mg}$ NHS. After stirred for 4 $\mathrm{h}$ for reaction, the system was added with $10 \mathrm{mg}$ RGD polypeptide. Next, the mixture was further stirred overnight for complete reaction. Then, the obtained product was transferred into a dialysis sack (MWCO: $1000 \mathrm{Da}$ ) for purification. The targeted nanoparticles (CMCh-BAPERGD@ICG) were obtained after lyophilized. Light was avoided during the whole process. Doxorubicin-loaded (DOX) nanoparticles were prepared according to the same procedure.

\section{Characteristics of CMCh-BAPE- RGD@ICG Nanoparticles}

The chemical structure of $\mathrm{CMCh}, \mathrm{CMCh}-\mathrm{BAPE}$ and CMCh-BAPE-RGD were analyzed by nuclear magnetic resonance $\left({ }^{1} \mathrm{H}\right.$ NMR) spectrometer (AVANCE III 500M, Bruker, Germany). Fourier transform infra-red (FTIR) spectrometer (VERTEX 70, Bruker, Germany) was applied to determine its functional groups. The morphology images of the nanoparticles were obtained by transmission electron microscopy (TEM, JEM-2010F, JEOL Ltd., Tokyo, Japan). The mean hydrodynamic diameter and size distribution were recorded by dynamic light scattering (Zetasizer Nano-ZS90, Malvern Instruments Ltd., Worcestershire, $\mathrm{UK})$ at $25^{\circ} \mathrm{C}$. The changes in size distribution after treated by $\mathrm{H}_{2} \mathrm{O}_{2}(1 \mathrm{mM})$ were also recorded.

\section{Drug Loading Efficiency}

The ICG loading efficiency (LE) was calculated via UVvis spectrophotometric method. In brief, a series of ICG solutions with different concentrations were prepared and the standard absorption curve of pure ICG in ultra-pure water was obtained by a UV-vis spectrometer (UV3100PC, Mapada Instruments, Shanghai, China). Set the $\lambda_{\max }$ at $790 \mathrm{~nm}$. The loaded ICG dose in CMCh-BAPERGD@ICG was determined by the absorption value. The formulas used were as follows:

$$
\mathrm{LE}(\%)=\frac{I C G_{\text {loaded }}}{\text { weight }_{\text {nanoparticles }}} \times 100 \%
$$




\section{In vitro ROS-Responsive Leakage \\ Assessment}

The fluorescence-based doxorubicin (DOX) leakage experiment was conducted to simulate the release and ROS-responsive release of ICG from nanoparticles. The DOX nanoparticles were prepared as mentioned above. Then, $1 \mathrm{~mL}$ pure water containing $6 \mathrm{mg}$ samples in a pretreated dialysis bag (MWCO: $1000 \mathrm{Da}$ ) was dialyzed against $\mathrm{H}_{2} \mathrm{O}_{2}$ solutions $(0 \mathrm{mM}$ or $1 \mathrm{mM})$ in a $15 \mathrm{~mL}$ centrifuge tube. At different time intervals, $1 \mathrm{~mL}$ dialysate sample was taken for obtaining the concentration of DOX by measuring the maximum DOX absorbance $(\lambda=493 \mathrm{~nm})$. The dialysate sample was returned to the centrifuge tube immediately after detection. The following formula was applied for cumulative release (\%) calculation:

$$
\text { cumulative DOX release }(\%)=\frac{A_{i}-A_{t}}{A_{i}} \times 100 \%
$$

Where $A_{i}$ was the initial absorbance value, and $A_{t}$ was the absorbance value detected at different time intervals.

\section{In vitro Photostability Evaluation}

A UV-vis spectrometer and a fluorescence spectrometer (HR2000+, Ocean Optics) were employed to determine the absorption and emission spectra of ICG and CMCh-BAPERGD@ICG (equivalent ICG concentration: $10 \mu \mathrm{g} / \mathrm{mL}$ ), respectively. The photostability was evaluated by detecting the changes in absorption and emission spectra at selected time intervals. All of the samples were dissolved in pure water and stored in the dark at $25^{\circ} \mathrm{C}$.

\section{In vitro Photothermal Efficiency Measurement}

The photothermal properties of different materials were evaluated. One hundred microliters of PBS containing free ICG, CMCh-BAPE-RGD, or CMCh-BAPE-RGD@ICG (the equivalent ICG concentration was $20 \mu \mathrm{g} / \mathrm{mL}$ ) were placed into Eppendorf tubes, respectively. The blank control was PBS without samples. An $808 \mathrm{~nm}$ laser with $1 \mathrm{~W} / \mathrm{cm}^{2}$ energy was applied for irradiation for $5 \mathrm{~min}$. The temperature was recorded every 10 seconds to compare the photothermal effects of different samples in vitro.

In addition, the effect of concentration on the photothermal effect of the material was explored. Generally, different concentrations of CMCh-BAPE-RGD@ICG $(10,20,30$, and $40 \mu \mathrm{g} / \mathrm{mL})$ were dissolved in pure water and placed into Eppendorf tubes, respectively. The blank control was pure water without samples. Then, samples were irradiated and the temperature was recorded by an infrared thermal imager (Fotric 222, Shanghai, China).

\section{Cell Culture and Mice}

L929 cells (a mouse fibroblastic cell line, ATCC) were cultured in RPMI 1640 medium while NIH/3T3 cells (a mouse fibroblastic cell line, ATCC) and SGC7901 cells (a human gastric cancer cell line, ATCC) were incubated in Dulbecco's modified Eagle's medium (DMEM) at $37^{\circ} \mathrm{C}$ in a humidified atmosphere containing $5 \% \mathrm{CO}_{2}$. All of the media was supplemented with $10 \%$ FBS, $1 \%$ penicillin, and $1 \%$ streptomycin. The experimental female BALB/c nude mice were obtained from Beijing Virton Li Hua Experimental Animal Technology Co., Ltd (Beijing, China) and raised in the specific pathogenfree (SPF) animal room. Before experimentation, all mice were raised for one week to acclimatize to the environment. All mice experiments were conducted following the guideline of the Ethics Committee of the Institutional Animal Care and Use Subcommittee of the Third Hospital of Sun Yat-sen University and the committee approved this study.

\section{Intracellular ROS Level Measurement}

The intracellular ROS levels of SGC7901 cells and NIH/3T3 cells (negative control) were determined by ROS detection assay kit. Briefly, cells were harvested and incubated with 10 $\mu \mathrm{M}$ DCFH-DA for $20 \mathrm{~min}$ at $37^{\circ} \mathrm{C}$ in the darkness, shaking slightly every $5 \mathrm{~min}$. Then, the cells were washed thrice with serum-free medium to remove unreacted DCFH-DA probe. The fluorescence was visualized immediately under a fluorescence microscope (Nikon, Tokyo, Japan) and quantified by flow cytometry (BD Accuri, USA).

\section{Cellular Uptake}

The internalization of CMCh-BAPE@ICG and CMChBAPE-RGD@ICG was investigated by performing the confocal laser scanning microscopy (CLSM, Zeiss LSM 710, Germany) and flow cytometry. In detail, SGC7901 cells were harvested in the logarithmic growth phase and seeded into the $35-\mathrm{mm}$ cell petri dishes (Nest, 801002$)\left(5 \times 10^{4}\right.$ cells/ dish) at $37^{\circ} \mathrm{C}$ and cultured for $24 \mathrm{~h}$ prior to the experiment. Then, the medium was replaced and supplemented with CMCh-BAPE@ICG or CMCh-BAPE-RGD@ICG (ICG concentration was $10 \mu \mathrm{g} / \mathrm{mL}$ ), respectively. After incubated for 6 $\mathrm{h}$, cells were washed with PBS and fixed with paraformaldehyde (4\%), followed by added with $1 \mu \mathrm{L}$ DAPI for staining the nuclei. Next, cells were gently washed with PBS and the cellular internalization was imaged under CLSM. Red and 
blue fluorescence emissions from ICG and DAPI were acquired at $\lambda_{\mathrm{ex}}=633 \mathrm{~nm}$ for ICG and $\lambda_{\mathrm{ex}}=405 \mathrm{~nm}$ for DAPI, respectively.

Flow cytometry was performed for further quantitative analysis. $5 \times 10^{4}$ SGC7901 cells were seeded into 24-well plates per well. Twenty-four hours later, the medium was replaced by fresh medium, respectively, supplemented with CMCh-BAPE@ICG or CMCh-BAPE-RGD@ICG and cultured for different time intervals (the equivalent ICG concentration was $10 \mu \mathrm{g} / \mathrm{mL}$ ). At each time interval ( $3 \mathrm{~h}$ and $6 \mathrm{~h}$ ), cells were gently washed three times, followed by trypsin digestion, centrifugation, and re-suspended in PBS. Finally, flow cytometry was applied to determine the fluorescence intensity of cells in each group and the corresponding fluorescence intensity was quantified by FlowJoV10 software.

\section{In vitro Cytotoxicity and Anticancer Activity Assessment}

CCK-8 assay was applied for determining the toxicity of CMCh-BAPE-RGD@ICG on L929 cells. Generally, 5000 L929 cells in the logarithmic phase were harvested, resuspended, and seeded into 96-well plates for overnight incubation. Then, the medium was replaced by fresh medium supplemented with CMCh-BAPE-RGD@ICG at different concentrations $(10,20,40,80,160,320$, and $500 \mu \mathrm{g} / \mathrm{mL})$. After $24 \mathrm{~h}$ incubation, the cell viabilities were measured based on the product protocol. For the photocytotoxicity effect assessment, SGC7901 cells seeded into 96-well plates, and the medium was added with CMCh-BAPERGD@ICG at various concentrations (ICG equivalent concentration: $0,5,10,20$, and $40 \mu \mathrm{g} / \mathrm{mL}$ ). After 6 $\mathrm{h}$ incubating, the medium was replaced and irradiated for $5 \mathrm{~min}$ by an $808 \mathrm{~nm}$ laser with $1.0 \mathrm{~W} / \mathrm{cm}^{2}$ energy. Cells without laser irradiation were set as the control group. Twenty-four hours later, the cell survival ratios were calculated. Meanwhile, for the comparison of photocytotoxicity effects of different materials, SGC7901 cells were treated with PBS, ICG, or CMCh-BAPE-RGD@ICG for $6 \mathrm{~h}$ (ICG equivalent concentration: $20 \mu \mathrm{g} / \mathrm{mL}$ ). Then, cells were treated with laser and the illuminated condition was consistent with the mentioned above. Twenty-four hours later, the photocytotoxicity was determined by CCK-8 assay. Flow cytometry with FITC-labeled Annexin V/propidium iodide (PI) double-staining assay was further performed for analysis of the apoptosis.
The live/dead staining assay was conducted for further analysis. Briefly, SGC7901 cells were treated with PBS, ICG, or CMCh-BAPE-RGD@ICG (an equivalent ICG concentration: $20 \mu \mathrm{g} / \mathrm{mL}$ ), followed by laser illumination as mentioned above. Twenty-four hours later, calcein AM and PI were added for staining. Then, the cells were gently rinsed by PBS three times and observed under the fluorescence microscope. The images were acquired at $\lambda_{\mathrm{ex}}=545$ $\mathrm{nm}$ and $\lambda_{\mathrm{ex}}=490 \mathrm{~nm}$ for PI and calcein AM, respectively.

\section{In vitro Blood Compatibility Assay}

First, hemolysis assay of erythrocytes was performed to assess the safety of CMCh-BAPE-RGD@ICG. Generally, red blood cells (RBCs) from a 6-week-old nude mouse were collected from fresh blood samples after centrifuged to remove the serum (5000 rpm, $5 \mathrm{~min}$ ). The RBCs were washed, resuspended, and diluted with PBS to adjust the final concentration at $16 \%$ (v: v). Next, $50 \mu \mathrm{L}$ RBC solutions were added to $1 \mathrm{~mL}$ PBS containing CMCh-BAPE-RGD@ICG with different concentrations $(0.01,0.1,0.5$, and $1 \mathrm{mg} / \mathrm{mL}), 1 \mathrm{~mL}$ pure water (positive control) or $1 \mathrm{~mL}$ PBS (negative control), respectively. After being incubated for a period of time $(3 \mathrm{~h}$, $5 \mathrm{~h}, 8 \mathrm{~h}, 18 \mathrm{~h}$, and $24 \mathrm{~h}$ ), the mixtures were centrifuged (1000 rpm, $5 \mathrm{~min}$ ) and the supernatants containing lysed RBCs were collected for absorbance values determination at $540 \mathrm{~nm}$. The hemolysis was calculated as follows:

$$
\text { Hemolysis }(\%)=\frac{A_{t}-A_{n}}{A_{p}-A_{n}} \times 100 \%
$$

Note that $A_{t}$ was the absorbance of samples incubated with nanoparticles measured at different time intervals. $A_{p}$ was the absorbance of samples incubated with pure water and $A_{n}$ was the absorbance of samples incubated with PBS.

To further observe the effect of nanoparticles on RBCs, the erythrocyte morphology was determined. Briefly, the RBCs were obtained as mentioned before and added to $1 \mathrm{~mL}$ PBS containing CMCh-BAPE-RGD@ICG with different concentrations $(0.01,0.1,0.5$, and $1 \mathrm{mg} / \mathrm{mL})$. After incubated at $37^{\circ} \mathrm{C}$ for $15 \mathrm{~min}$, the mixture was centrifuged for $5 \mathrm{~min}$ to collect the precipitation. The precipitation was fixed by paraformaldehyde, followed by resuspension, dehydration, airing and observed under an Ultra-55 scanning electron microscope (Zeiss, Germany).

\section{In vivo NIR Fluorescence Imaging}

$2 \times 10^{6}$ SGC7901 cells $(0.2 \mathrm{~mL}$ in PBS $)$ were injected into the left subcutaneous armpit areas to develop a tumor-bearing 
mice model. The tumor volume was calculated $(V=0.5 \times \mathrm{A} \times$ $\mathrm{B}^{2}$, A stands for longest diameter and B stands for the shortest diameter) and the size was recorded three times a week. When the volume reached $\approx 100 \mathrm{~mm}^{3}$, mice were randomly divided into three groups $(n=3)$, followed by intravenous administration with CMCh-BAPE@ICG or CMCh-BAPE-RGD@ICG via tail vein (an equivalent ICG dose: $2 \mathrm{mg} / \mathrm{kg}$ ), respectively. The experimental mice were anesthetized with $2 \%$ isoflurane prior to the imaging. At $0.5,1,3,5,8 \mathrm{~h}$ post-injection, the fluorescent images were acquired by the Bruker In vivo FX PRO system (Bruker company, Germany). The parameters were set at $\lambda_{\mathrm{ex}}=760 \mathrm{~nm}$ and $\lambda_{\mathrm{em}}=830 \mathrm{~nm}$. All of the experimental mice were sacrificed and the tumors and major organs were isolated and visualized under the same conditions as described above. And Bruker molecular imaging software was used to quantify the fluorescence intensity at selected ROIs.

\section{In vivo Photothermal Therapy Evaluation}

When the tumor volumes developed to approximately $100 \mathrm{~mm}^{3}$, mice were randomly divided into 8 groups (n $=3)$. Then, the experimental mice were injected with (2 $\mathrm{mg} / \mathrm{kg}$ equivalent ICG dose for each mouse) (a) PBS, (b) CMCh-BAPE@ICG, (c) CMCh-BAPE-RGD@ICG, (d) PBS+laser, (e) CMCh-BAPE@ICG +laser, (f) CMChBAPE-RGD@ICG+laser, (g) ICG, (h) ICG+laser, respectively. An $808 \mathrm{~nm}$ laser with $1.0 \mathrm{~W} / \mathrm{cm}^{2}$ energy was applied for irradiation for $10 \mathrm{~min}$. The materials were intravenous injected every 2 days and the treatment lasted for 21 days. Meanwhile, the bodyweight of mice and the volume of tumors were detected every other day. After the experimental period, all tumor-bearing mice were killed, followed by blood collection, resection of the tumors and major organs for further analysis.

\section{Histological Analysis}

The isolated tissues were immersed in paraformaldehyde solution (4\%) at least $24 \mathrm{~h}$ for tissue fixation, followed by dehydration with ethanol and dimethyl benzene and paraffin embedding. The paraffin-embedded tissues were cut into sections, followed by H\&E staining.

TUNEL assay was performed to assess the cellular apoptosis. In all, tissue sections were incubated with proteinase $\mathrm{K}$ and washed with PBS. Then, the TUNEL reaction mixture was used according to the production protocol. Finally, the cellular apoptosis was visualized under a fluorescence microscope. Furthermore, Ki-67 immunostaining was also conducted to observe the proliferation of tumor tissues.

\section{Statistical Analysis}

All values were displayed as mean \pm SD, and SPSS 21.0 software (Chicago, IL, USA) was used for further statistical analysis. T-test was applied for comparisons between two groups whereas one-way analysis of variance (ANOVA) and post hoc Tukey analysis were performed for comparing multiple groups. The differences were considered significant when (*) $P<0.05,(* *) P<0.01$ and $(* * *) P<0.001$.

\section{Results and Discussion Preparation and Characterization of Nanoparticles}

In this work, the amphiphilic nanoparticles with co-encapsulated ICG for NIR imaging and PTT were obtained by bromination reaction and nucleophilic substitution reaction of $\mathrm{CMCh}$ and BAPE. Meanwhile, to enhance their targeting and penetration in solid tumors, RGD polypeptides, which can specifically target integrin $\alpha_{v} \beta_{3}$, were further conjugated onto the surface of CMCh-BAPE. The resultant products were characterized by ${ }^{1} \mathrm{H}$ NMR as shown in Figure 1C. Resonance peak at $3.90 \sim 4.20 \mathrm{ppm}$ attributed to the $\left(\mathrm{O}-\mathrm{CH}_{2}-\mathrm{C}=\mathrm{O}\right)$ of $\mathrm{CMCh}$, and 7.2 7.3 ppm and 7.6 ppm corresponded to the benzene ring on the phenylboronic acid pinacol ester and the pinacol ester, which indicated the successful synthesis of CMCh-BAPE. ${ }^{41}$ Meanwhile, $7.4 \mathrm{ppm}$ was the characteristic peak of hydrogen atoms on the benzene ring of RGD, and 1.4 2.0 ppm was a series of proton peaks on RGD, which evidenced RGD successful functionalization.

Meanwhile, FTIR spectra of $\mathrm{CMCh}$, BAPE, and CMCh-BAPE were demonstrated in Figure S1. The FTIR spectrum of CMCh-BAPE presented peak at $3600 \sim 3200 \mathrm{~cm}^{-1}$ was assigned to the amide bond; peak at $3100 \sim 3000 \mathrm{~cm}^{-1}$ was related to the stretching vibration of aromatic $\left(V_{=\mathrm{CH}}\right)$; peak at $3000 \sim 2850 \mathrm{~cm}^{-1}$ was the main characteristic absorption band of alkane; peak at $1650 \sim 1500 \mathrm{~cm}^{-1}$ was corresponding to the benzene ring skeleton vibration $\left(V_{\mathrm{C}=\mathrm{C}}\right)$; peak at $1250-1000 \mathrm{~cm}^{-1}$ belonged to the in-plane bending vibration of aromatic hydrogen $\left(\beta_{=C-H}\right)$. It can be noted that these characteristic peaks were obviously enhanced compared with $\mathrm{CMCh}$, indicating that $\mathrm{CMCh}$ has been successfully coupled with BAPE by amide bond. ${ }^{41}$ 
A

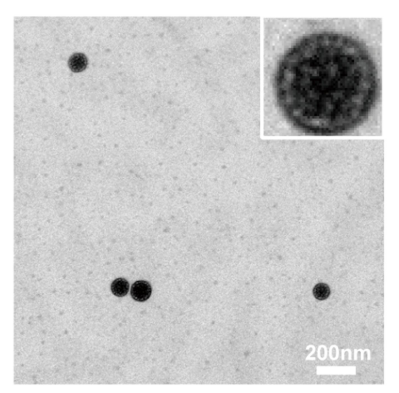

D

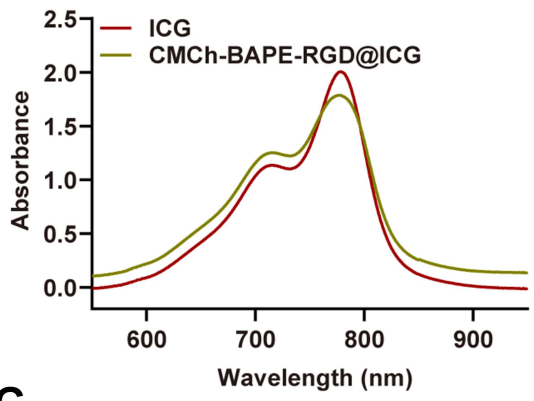

G

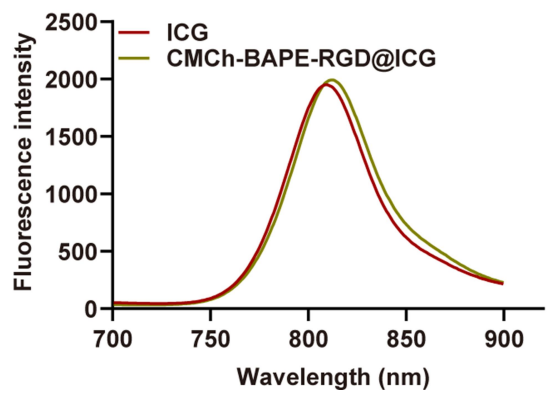

B

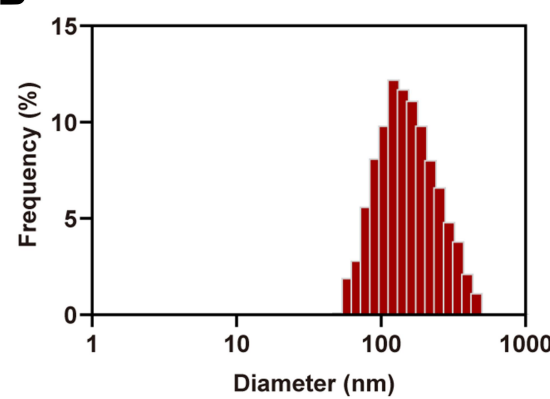

E

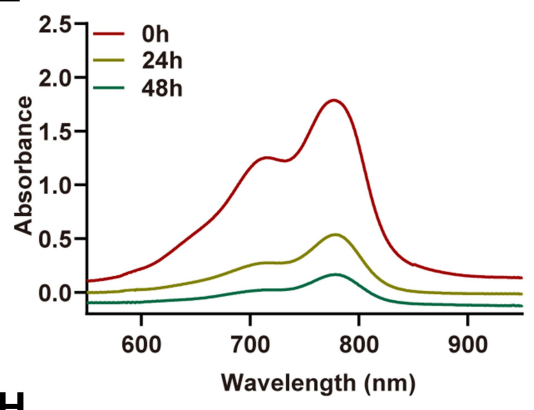

H

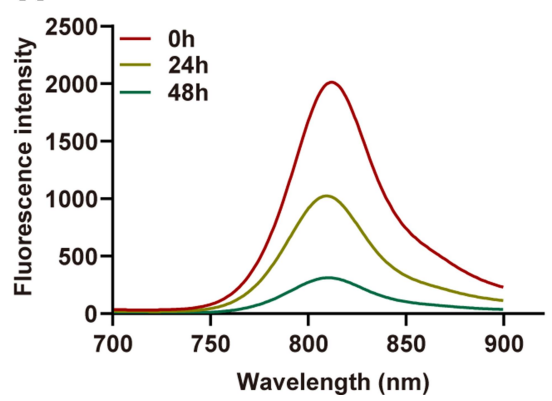

C

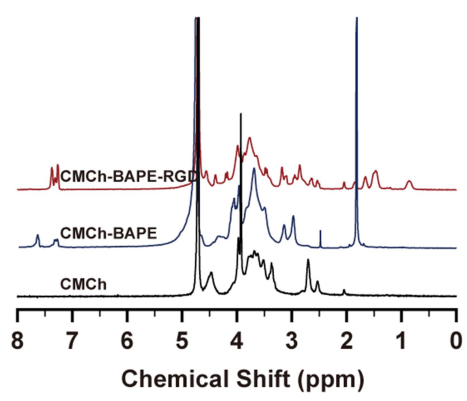

$\mathbf{F}$
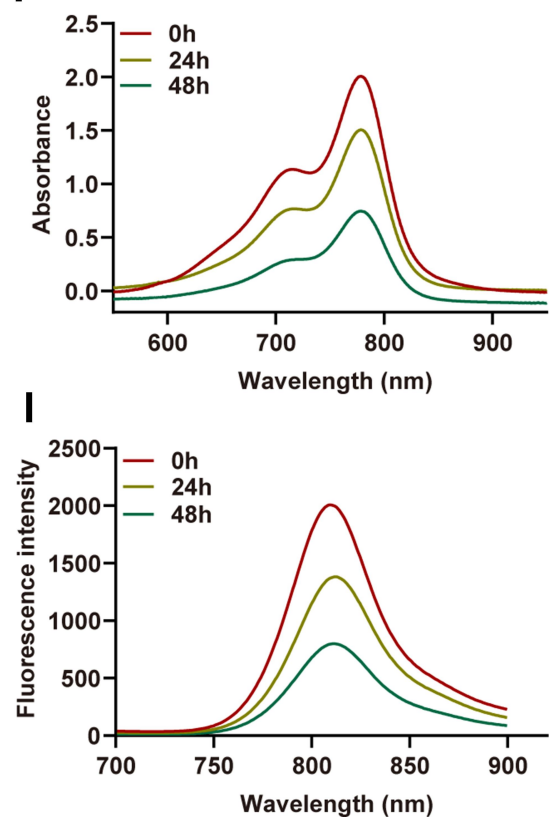

Figure I (A) TEM images of CMCh-BAPE-RGD@ICG. (B) Diameter distribution of CMCh-BAPE-RGD@ICG. (C) 'H-NMR of CMCh-BAPE-RGD@ICG. (D) UV-vis absorption spectra and (G) emission spectra of ICG and CMCh-BAPE-RGD@ICG. Changes of absorption and emission spectrum of ICG (E and H) and CMCh-BAPERGD@ICG (F and I) in aqueous solution within 48 h.

To determine the formation of the resultant products, TEM was employed to observe their morphology. CMChBAPE-RGD@ICG appeared individual spherical coreshell structure and homogeneously distributed as expected (Figure 1A). The size was about $120 \mathrm{~nm}$. DLS was further applied to confirm the particle size. As shown in Figure $1 \mathrm{~B}$, the average hydrodynamic diameter of CMCh-BAPERGD@ICG was $151 \mathrm{~nm}$ with a polydispersity index (PDI) of 0.278. Previous studies revealed that particles less than $200 \mathrm{~nm}$ tended to accumulate at tumor sites. ${ }^{30,42}$ The $\approx 150$ $\mathrm{nm}$ size indicated that obtained nanoparticles were suitable for drug delivery. ${ }^{43}$ Furthermore, the LE of ICG was 7.5\%.

The spectral properties were further determined. As shown in Figure 1D and G, similar absorption and emission spectra were observed in both ICG and CMCh-BAPERGD@ICG group, indicating that the nanoparticles had a slight effect on the spectral properties of free ICG.
Besides, due to the saturation of the double bonds in the conjugated chain, ICG tends to degrade in aqueous solution. ${ }^{38}$ Meanwhile, once the concentration exceeds $3.9 \mathrm{mg} / \mathrm{l}$, ICG will self-quenched. ${ }^{14,44}$ Considering all the above factors, the spectra of ICG and CMCh-BAPERGD@ICG were further characterized after reserving in the dark at $4^{\circ} \mathrm{C}$ within $48 \mathrm{~h}$. The results showed that the absorption and fluorescence intensity of CMCh-BAPE-RGD@ICG remained $37.2 \%$ and $39.9 \%$ of the initial value (Figure $1 \mathrm{~F}$ and I), while $\approx 90 \%$ absorption and fluorescence intensity of free ICG lost after $48 \mathrm{~h}$ (Figure 1E and H). Obviously, the encapsulation of ICG improved its stability for potential clinical applications.

Due to the high level of ROS environment in cancer cells, boronic ester, a ROS-responsive linkage, would be hydrolyzed, resulting in the decomposition of BAPE and the release of ICG in the tumor site. ${ }^{45}$ To investigate the ROS response 
A
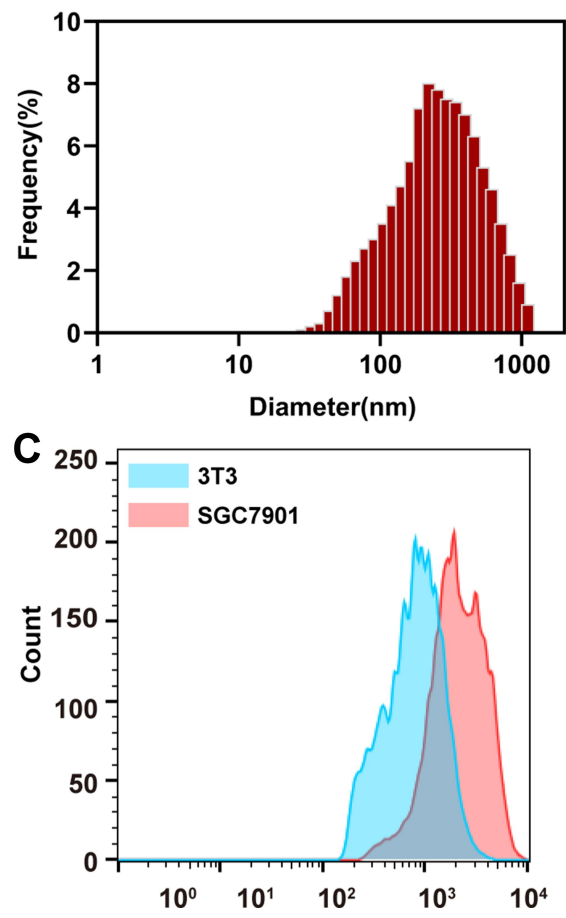

B

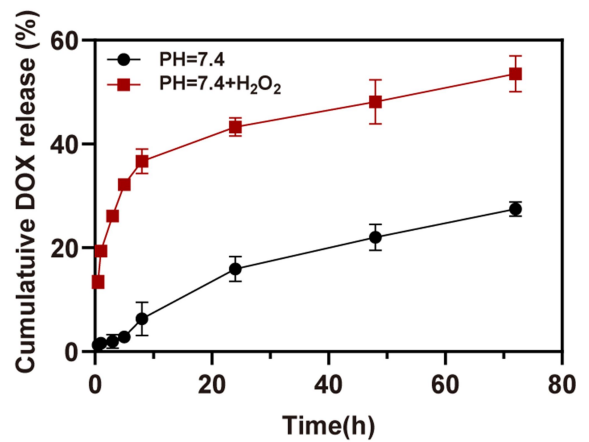

D

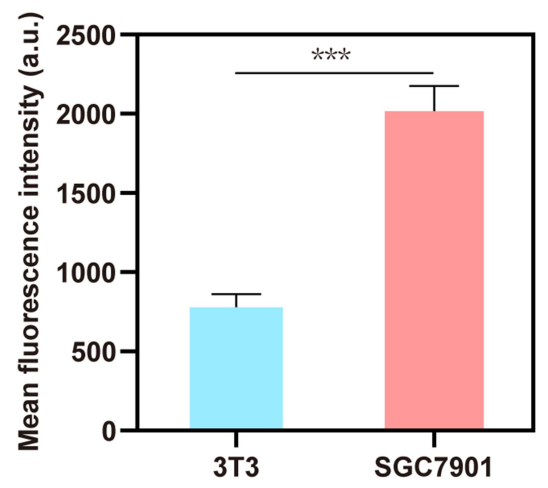

Figure 2 (A) Diameter distribution of CMCh-BAPE-RGD@ICG in the present of $\mathrm{H}_{2} \mathrm{O}_{2}$. (B) ROS-responsive leakage assessment of DOX in vitro. (C) Flow cytometry analysis of ROS level. (D) Mean fluorescence intensity from flow cytometry analysis $(n=3)$. (***) $P<0.00 \mathrm{I}$.

behavior of CMCh-BAPE-RGD@ICG, 1 mM $\mathrm{H}_{2} \mathrm{O}_{2}$ was used to simulate the high ROS environment in vivo. As shown in Figure 2A, the diameter increased to $210 \mathrm{~nm}$ (PDI: 0.43) in the presence of $\mathrm{H}_{2} \mathrm{O}_{2}$, indicating the fracture of the nanoparticles. Meanwhile, we further performed a drug release experiment. Considering the instability of ICG, DOX was used to simulate the ROS-triggered leakage behavior of ICG (Figure 2B). Under the condition of $\mathrm{PH}=7.4$, only $28 \%$ DOX release was observed. However, $\approx 55 \%$ DOX released from the nanoparticles in the presence of $\mathrm{H}_{2} \mathrm{O}_{2}$ over a period of $72 \mathrm{~h}$. Additionally, the intracellular ROS level was determined. As shown in Figure $2 \mathrm{C}$ and $\mathrm{D}$, the ROS level in SGC7901 cells was about thrice higher than that in 3T3 cells. CLSM also demonstrated similar results (Figure S2). These data indicated that the obtained nanoparticles possessed the character of ROS-responsive leakage for further investigation of SGC7901 cells.

Next, the photothermal conversion capability of these ICG complex was assessed by being exposed to NIR laser. Under the $1 \mathrm{~W} / \mathrm{cm}^{2}$ energy irradiation, the temperature increased rapidly and reached the maximum at $3 \mathrm{~min}$ in $\mathrm{ICG}$ and CMCh-BAPE-RGD@ICG group, which was $47.6^{\circ} \mathrm{C}$ and $48.5^{\circ} \mathrm{C}$, respectively, whereas the temperature increases of phosphate buffer saline and CMCh-BAPE-RGD were negligible (Figure 3A and $\mathrm{C}$ ). This result suggested that the original photothermal response of ICG was not affected by CMCh-BAPE-RGD particles. Intriguingly, the temperature gradually dropped after 3 minutes because of intermolecular quenching of ICG. ${ }^{44}$ Besides, the photothermal performance of CMCh-BAPE-RGD@ICG was positively correlated with the concentration within a certain range (Figure $3 \mathrm{~B}$ ).

\section{Enhanced Cellular Uptake of RGD-Modified Nanoparticles}

The cellular internalization process of free ICG and nanoparticles was evaluated in SGC7901 gastric cancer cells by CLSM and flow cytometry. For CLSM, the red fluorescence signal emitted by ICG from SGC7901 cells showed significantly stronger than that of free ICG or CMCh-BAPE@ICG groups after incubating with CMCh-BAPE-RGD@ICG for 6 $\mathrm{h}$ (Figure 4D), which indicated that CMCh-BAPERGD@ICG was largely internalized by SGC7901 cells. To further verify the enhanced cellular uptake of RGD-modified nanoparticles, flow cytometry was performed. As shown in Figure 4A and B, a time-dependent internalization process of CMCh-BAPE-RGD@ICG was demonstrated. Quantitatively, compared with other groups, the mean fluorescence intensity of the CMCh-BAPE-RGD@ICG group was significantly 
A

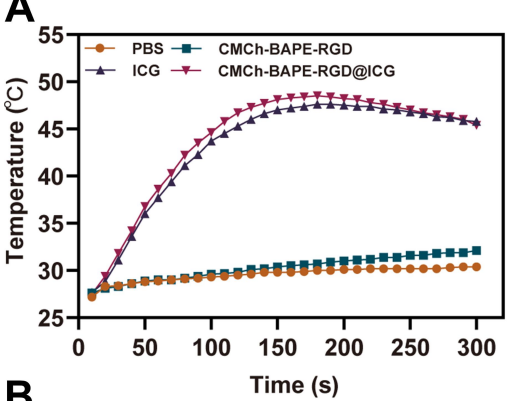

B

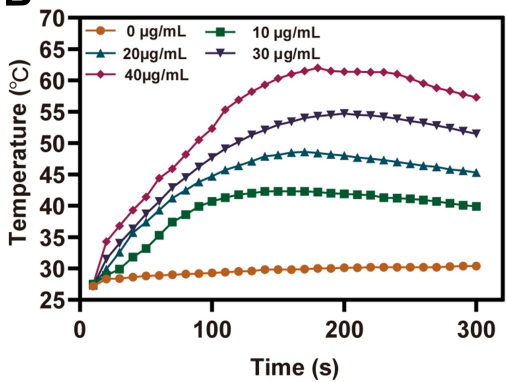

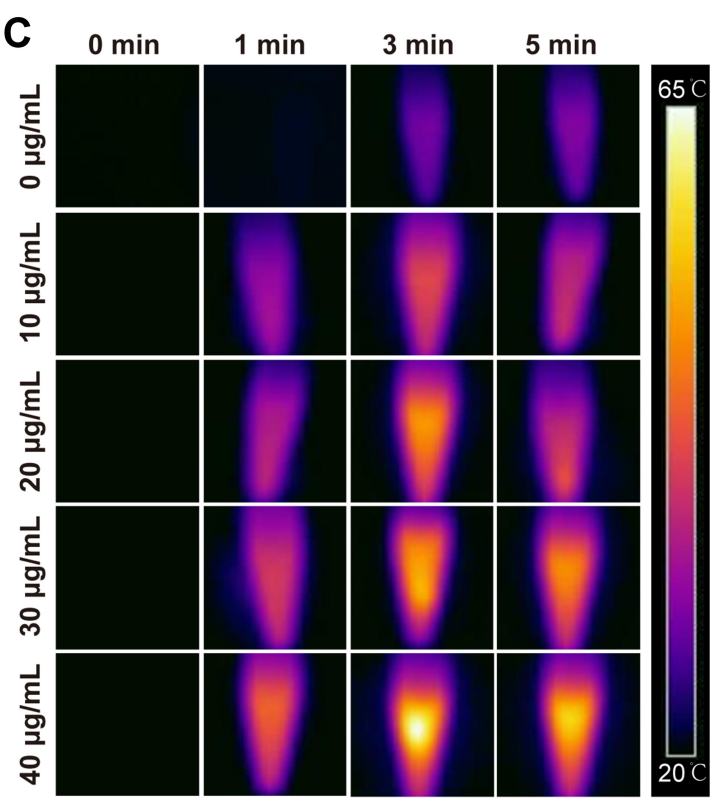

Figure 3 (A) Optothermal heating curve of PBS, ICG, CMCh-BAPE@ICG and CMCh-BAPE-RGD@ICG. (B) Temperature rise profile of CMCh-BAPE-RGD@ICG with different concentrations. (C) Corresponding infrared thermographic images.

stronger at selected time intervals $(P<0.05)$. After 6 $\mathrm{h}$ incubation, the fluorescence intensity of the CMCh-BAPERGD@ICG group was nearly twice than that of the $\mathrm{CMCh}$ BAPE@ICG group (Figure 4C). Previous studies revealed that integrin $\alpha_{\mathrm{v}} \beta_{3}$ is widely expressed and may be a putative prognostic biomarker in gastric cancer tissues. ${ }^{36}$ Given the fact that RGD polypeptides have a strong affinity to integrin $\alpha_{v} \beta_{3}$ which is overexpressed on the surface of SGC7901 cells, it is reasonable for CMCh-BAPE-RGD@ICG to demonstrate enhanced cellular internalization. These results confirmed that this targeting strategy was suitable for improving the delivery of ICG to SGC7901 cells, and the improved cellular endocytosis was considered to enhance the eventual performance in tumor NIR imaging and photothermal therapy.

\section{In vitro Cytotoxicity and Anticancer Activity Assessment}

We assessed the cytotoxicity of CMCh-BAPE-RGD@ICG nanoparticles on L929 cells by CCK-8 assay. As demonstrated in Figure 5A, as the concentration of $\mathrm{CMCh}-$ BAPE-RGD@ICG increased, there was a negligible influence on the cell viabilities $(P>0.05)$. Even if the concentration was increased to $500 \mathrm{ug} / \mathrm{mL}$, the cell viability remained over $80 \%$, indicating good biocompatibility.

Next, CCK-8 assay based on SGC7901 cells was performed to assess the anticancer activity of $\mathrm{CMCh}-$
BAPE-RGD@ICG. As expected, CMCh-BAPERGD@ICG had negligible toxicity on SGC7901 cells without NIR irradiation. Nevertheless, upon 5 min NIR irradiation, the survival rates of SGC7901 cells in this group decreased remarkably $(P<0.05)$ when compared with PBS or free ICG group (Figure 5D). Simultaneously, the relative growth rates (RGR) of SGC7901 cells incubated with CMCh-BAPERGD@ICG declined gradually as the concentration increased (Figure 5C). When the amount of ICG reached $40 \mathrm{ug} / \mathrm{mL}$ (the equivalent ICG concentration), only $20 \%$ of the cells were alive $\left(\mathrm{IC}_{50}=18.37 \mathrm{ug} / \mathrm{mL}\right)$. As a control, NIR laser exposure alone did not result in inhibition in SGC7901 cells viability. Besides, the representative results through live/dead staining assay were demonstrated in Figure 5B, indicating higher cytotoxicity when treated with CMCh-BAPE-RGD@ICG combined with NIR irradiation. Flow cytometry with Annexin V-FITC/PI staining assay was conducted to further detect the apoptosis and necrosis induced by CMCh-BAPE-RGD@ICG in SGC7901 cells (Figure $5 \mathrm{E})$. Notably, the proportion of early and late apoptotic cells in the CMCh-BAPE-RGD@ICG + NIR irradiation group (45.21\%) was significantly higher in comparison with that of other groups $(2.84 \%$ and $28.76 \%)$. Thus, CMCh-BAPE-RGD@ICG nanoparticles demonstrated good performance in killing the SGC7901 cells by 
A

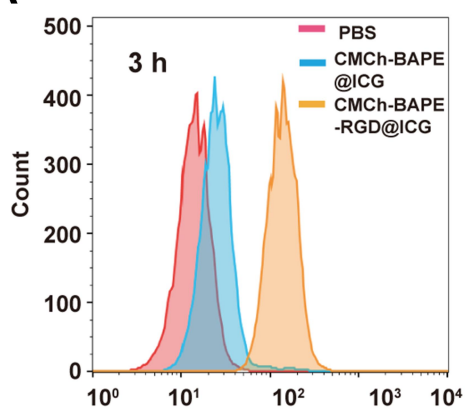

D

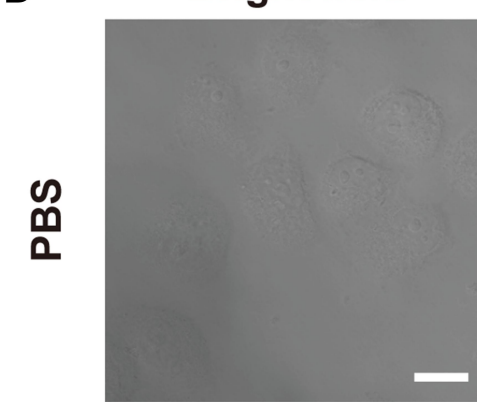

B

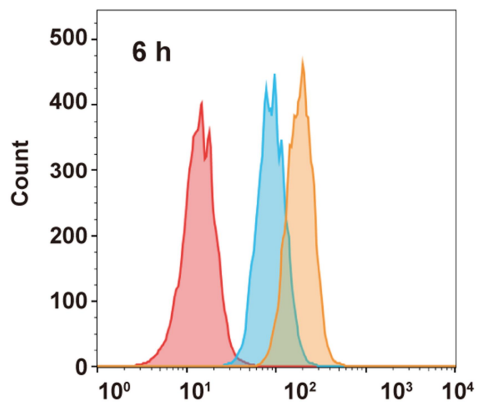

DAPI
C

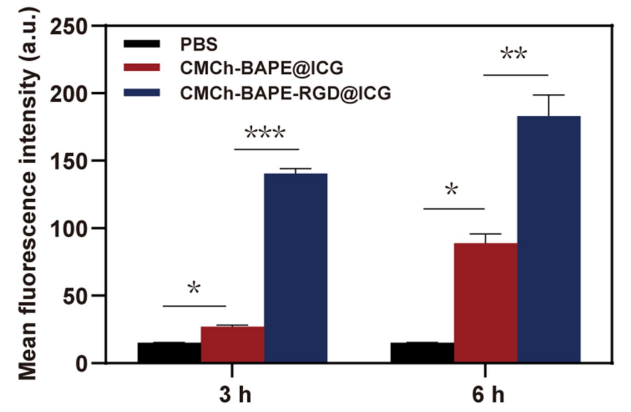

ICG
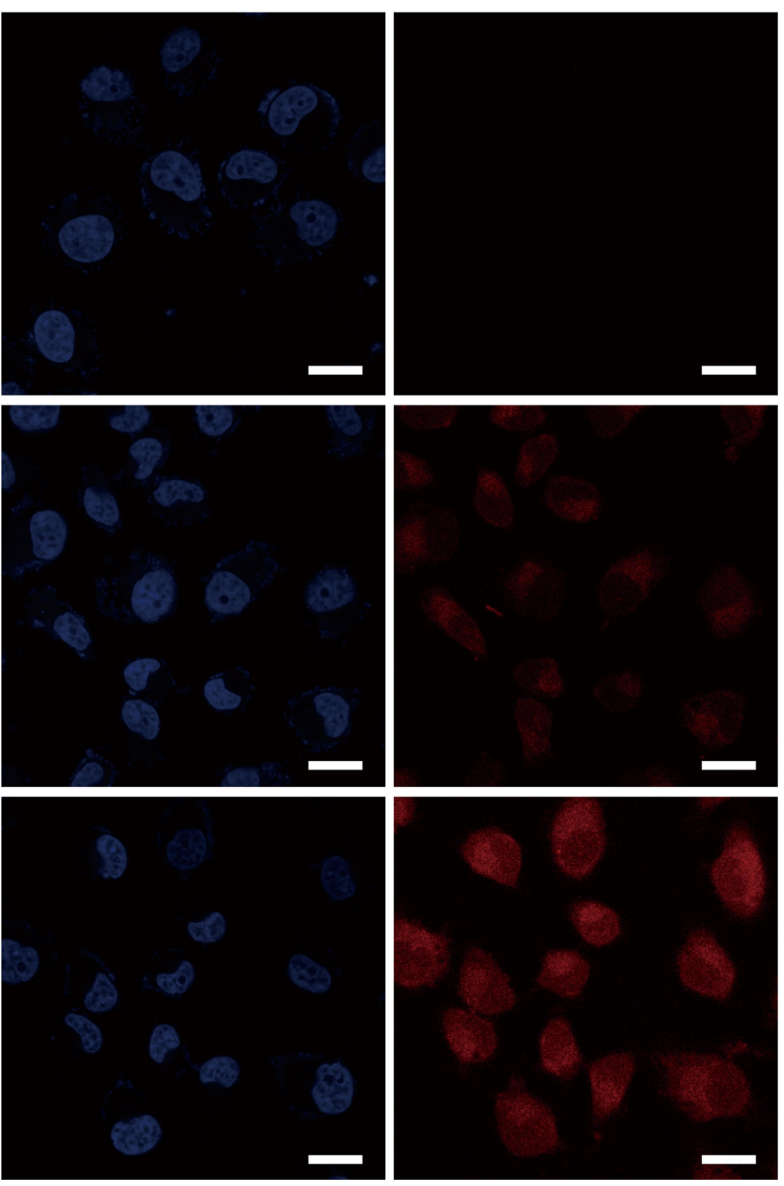

Merged
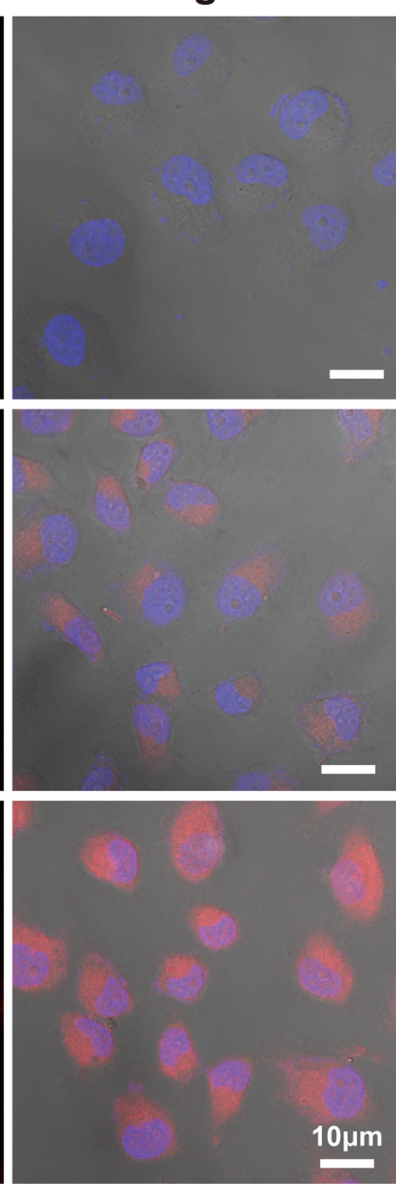

Figure 4 Flow cytometry analysis of ICG and CMCh-BAPE-RGD@ICG by SGC790I cells at $3 \mathrm{~h}$ (A) and $6 \mathrm{~h}$ (B). (C) Mean fluorescence intensity from flow cytometry analysis $(n=3)$. (D) Confocal laser scanning microscope images of SGC790I cells after treated with ICG and CMCh-BAPE-RGD@ICG for 6 h. (*) $P<0.05$, (**) $P<0.01$ and (***) $P<0.001$.

PTT, which was attributed to the high cellular internalization.

\section{In vitro Hemocompatibility Evaluation}

Hemolytic activity of erythrocytes is an alternative and reliable acute toxicity assay to evaluate the hemocompatibility of drugs for intravenous administration. ${ }^{46}$ The rupture of erythrocytes is highly associated with the physical and chemical properties of materials. An advising from The American Society for Testing and Materials (ASTM F756), materials could be divided into three categories according to the hemolytic ratio: non-hemolytic (hemolysis: 0-2\%), slightly hemolytic (hemolysis: 2-5\%), and hemolytic (hemolysis: $>5 \%$ ). Once the hemolysis rate exceeds $20 \%$, it will lead to a serious rupture of erythrocytes. ${ }^{47}$ As shown in Figure 6A, the hemolysis rate was less than $5 \%$ within a certain 


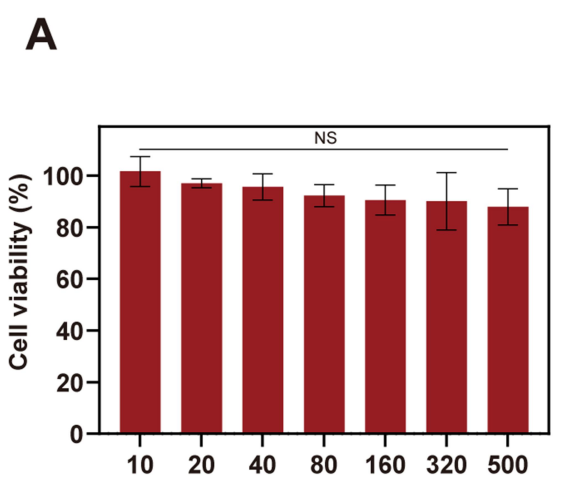

CMCh-BAPE-RGD@ICG concentration ( $\mu \mathrm{g} / \mathrm{mL})$

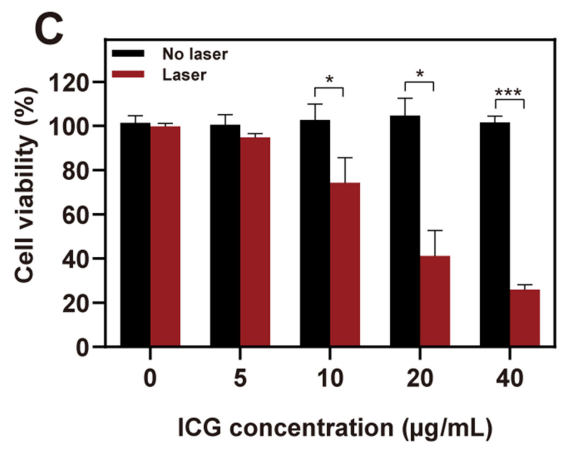

D

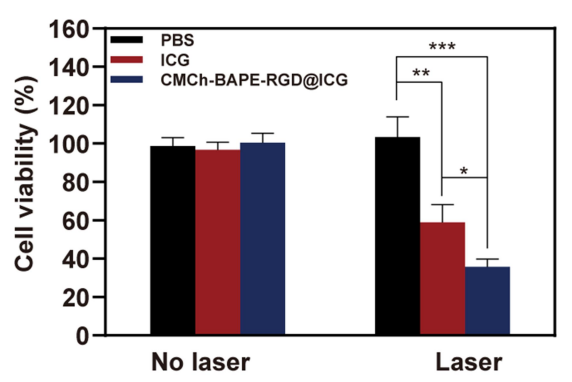

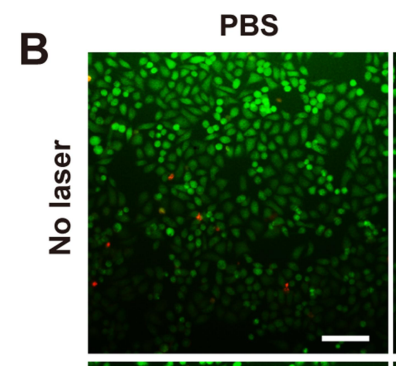

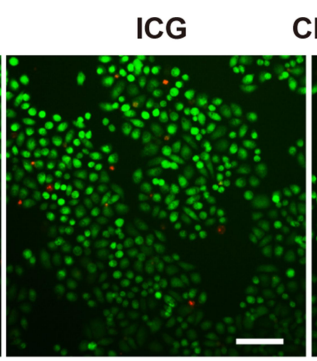

CMCh-BAPE-RGD@ICG
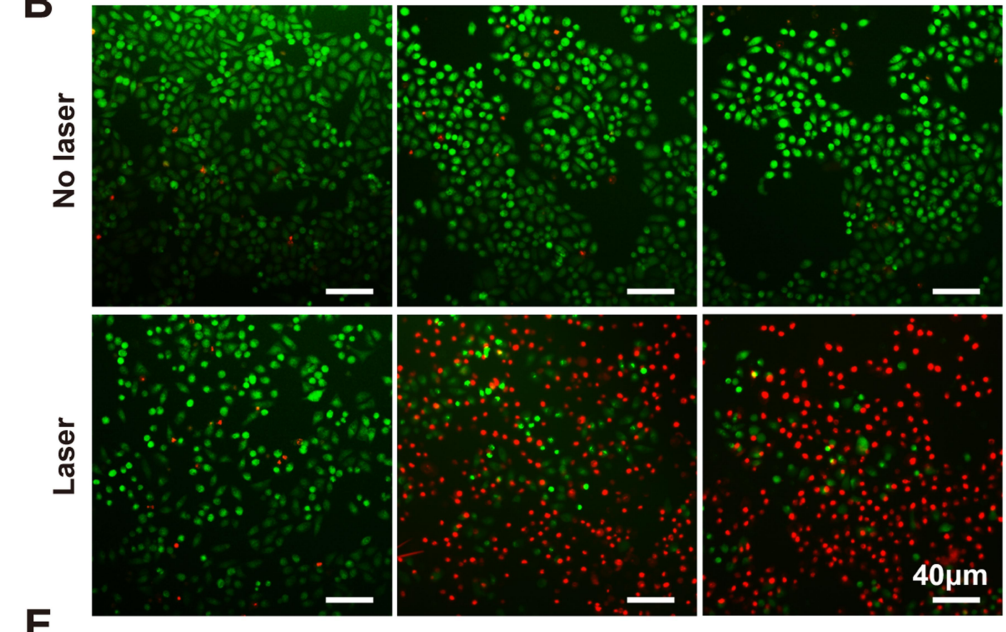

E
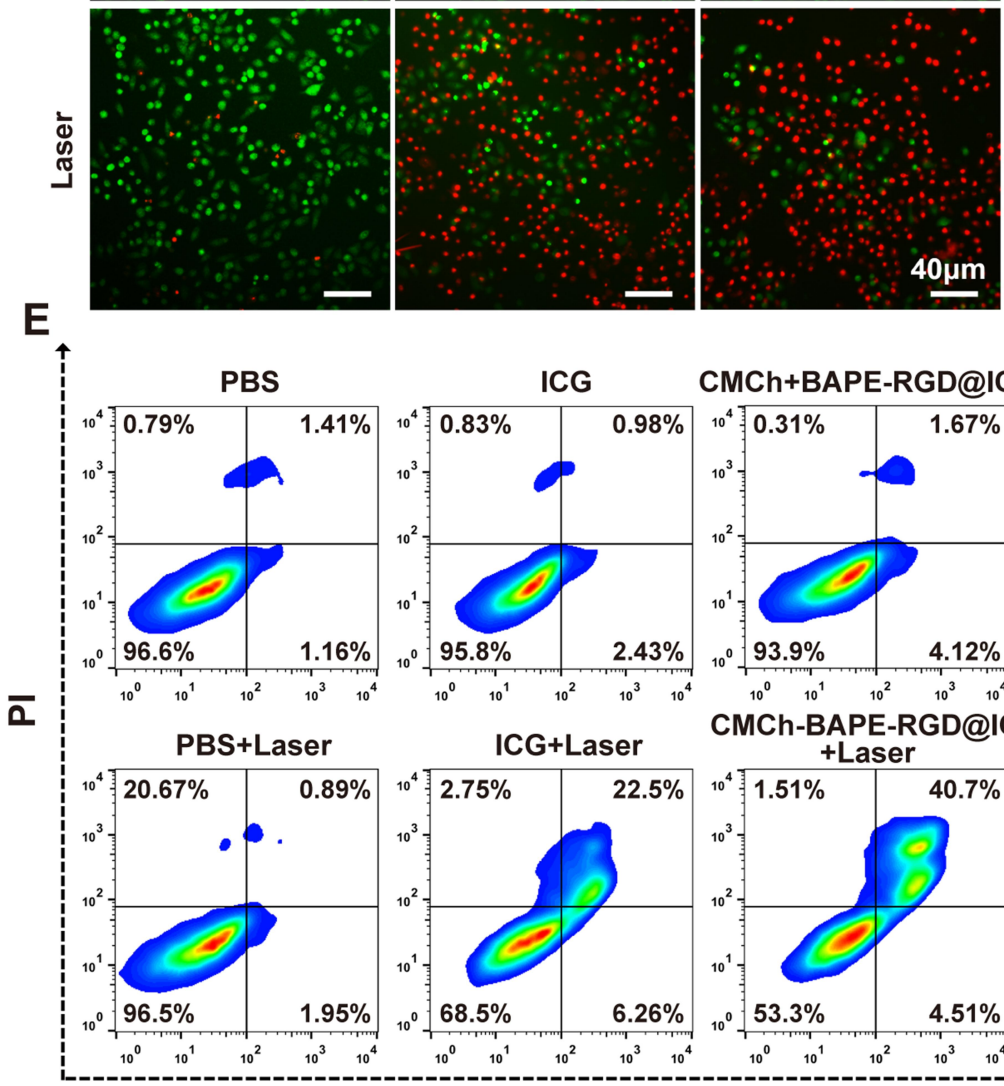

CMCh+BAPE-RGD@ICG

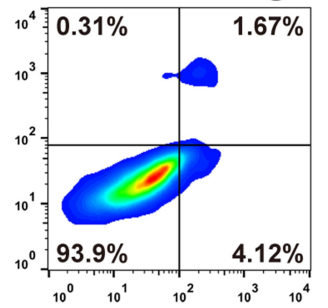

CMCh-BAPE-RGD@ICG

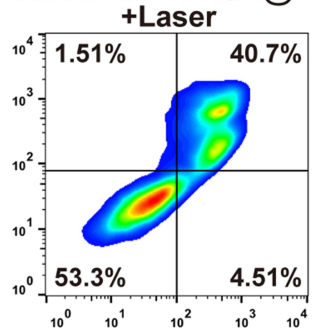

Annexin V-FITC

Figure 5 (A) CCK-8 assay of CMCh-BAPE-RGD@ICG on L929 cells with different concentrations. (B) Live/Dead staining imaging of SGC790I cells after treated with ICG or CMCh-BAPE-RGD@ICG with or without laser irradiation. (C) The viability of SGC790I cells incubated with CMCh-BAPE-RGD@ICG at different concentrations with or without laser irradiation. (D) SGC790I cell viability treated with PBS, ICG or CMCh-BAPE-RGD@ICG with or without laser irradiation. (E) Apoptosis analysis of SGC790I cells received the same treatment as $(D)$ by flow cytometry with Annexin V-FITC/PI double-staining assay. (NS) $P \geq 0.05$. $(*) P<0.05,(* *) P<0.0$ I and $(* * *) P<$ 0.001 .

concentration range. Meanwhile, the effects of CMCh-BAPERGD@ICG in different concentrations on the aggregation and morphology of erythrocytes were observed by SEM (Figure $6 \mathrm{~B})$. Even when the concentration reached $1 \mathrm{mg} / \mathrm{mL}$, the majority of erythrocytes could still maintain its normal disc shape with depression in the middle. Therefore, the hemolytic toxicity of CMCh-BAPE-RGD@ICG was permissible within its normal concentration range.

\section{In vivo NIR Fluorescence Imaging}

In view of the promising in vitro performance, we assessed whether the RGD-modified nanoparticle also demonstrated enhanced delivery and accumulation in gastric cancers in vivo. SGC7901 tumor-bearing mice were treated with nanoparticles with or without RGD, respectively, and the whole-body fluorescence signal was captured by an in vivo imaging system (IVIS). The results are illustrated in Figure 7A. Apparently, the fluorescence signals of the tumor site could be detected as early as $0.5 \mathrm{~h}$ post-injection of CMCh-BAPE-RGD@ICG. With time increasing, the fluorescence signal increased and reached a peak at 5 h. In contrast, CMCh-BAPE@ICG was mainly distributed in the liver and gastrointestinal tract, and only a weak fluorescence signal could be observed at the tumor site 3 

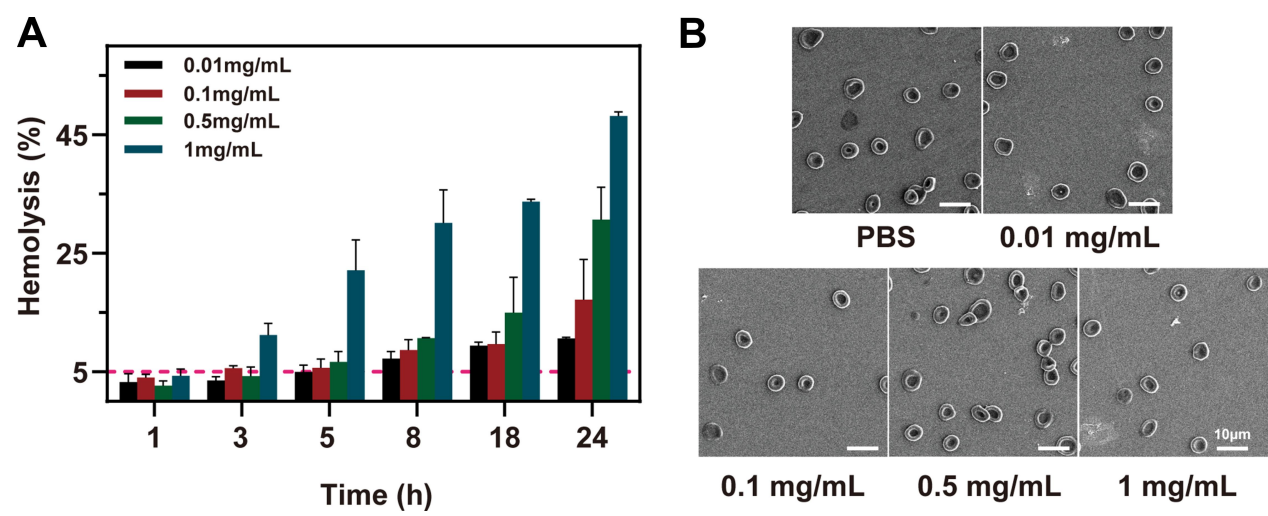

Figure 6 Hemolysis assay $(\mathbf{A})$ and SEM (B) of erythrocytes of CMCh-BAPE-RGD@ICG with different concentrations.

$\mathrm{h}$ after administration. At indicated time points, an evidently stronger fluorescence signal intensity was observed in mice treated with the CMCh-BAPE-RGD@ICG than other groups. Herein, the conjunction of RGD to the nanoparticles indeed efficiently improved the targeting ability to the tumors. Additionally, the aforementioned improved tumor accumulation was also verified by ex vivo fluorescent signals of the dissected tissues (Figure 7B). Intriguingly, the liver and kidney in the two groups also displayed relatively strong fluorescence signals, which was related to the metabolism of nanoparticles mainly through these organs. ${ }^{48}$ The semi-quantitative results of in vivo distribution were demonstrated in Figure S3. Collectively, CMCh-BAPE-RGD@ICG has improved tumor-specific accumulation and conducts efficient NIR imaging.

\section{In vivo Anti-Tumor Efficiency}

The above results demonstrated the potential of $\mathrm{CMCh}$ BAPE-RGD@ICG as an efficient and NIR imaging nanoparticles with promising photothermal therapy. Therefore, the anti-tumor efficiency of RGD-modified nanoparticles was investigated on SGC7901 subcutaneous tumor-bearing mice. Briefly, the experimental mice were treated with PBS, ICG, CMCh-BAPE@ICG (non-targeted), or CMCh-BAPE-RGD@ICG (targeted), followed with or without laser irradiation. During the 21-day treatment, there were no significant changes in the mouse body weight from each group, indicating minimal systematic toxicity of all treatments (Figures $8 \mathrm{~A}$ and S4A). Next, the volume of tumors was measured at regular intervals to monitor the anti-tumor effect of different therapies. As shown in Figures $8 \mathrm{~B}$ and $\mathrm{S} 4 \mathrm{~B}$, the strongest tumor-inhibitory effect was obtained in
CMCh-BAPE-RGD@ICG plus laser irradiation group $(P<0.001)$. More specifically, in the first 8 days of treatment, moderately restricted tumor growth was observed. After 9 days, the tumor growth of mice was significantly inhibited, eventually achieving nearly complete elimination. Meanwhile, the CMCh-BAPE@ICG plus laser irradiation demonstrated the second strongest anti-tumor effect. We ascribed it to the passive targeting ability of nanoparticles. After a period of 21-day experimentation, mice were killed and tumors were removed, weighed, and photographed (Figures 8C, D and S4), which further validated that CMCh-BAPE-RGD@ICG plus laser irradiation displayed the best tumor suppression effect. Additionally, a thermal infrared imaging camera was employed to monitor the changes of temperature in the tumor site upon laser irradiation. As shown in Figure 8E, the tumor temperature reached the maximum after 3 minutes of laser irradiation, $46.9^{\circ} \mathrm{C}$ in CMCh-BAPE-RGD@ICG group and $44.1^{\circ} \mathrm{C}$ in $\mathrm{CMCh}-$ BAPE@ICG group, respectively.

Subsequently, we further performed the histological analysis to assess the therapeutic effect of different treatments (Figures 8F and S4E). H\&E tumor sections suggested that CMCh-BAPE-RGD@ICG plus laser irradiation treatment led to the most severe structural damage and tissue necrosis. Similarly, the TUNEL assay indicated the most apoptotic tumor cells in this group after photothermal therapy. Besides, immunohistochemical staining for Ki67 antigen on tumor sections was performed to evaluate the proliferation extent of tumor cells. Apparently, a substantial decrease in Ki67 expression was observed in this group, indicating that the tumor proliferation activity was also markedly suppressed after treatment. 


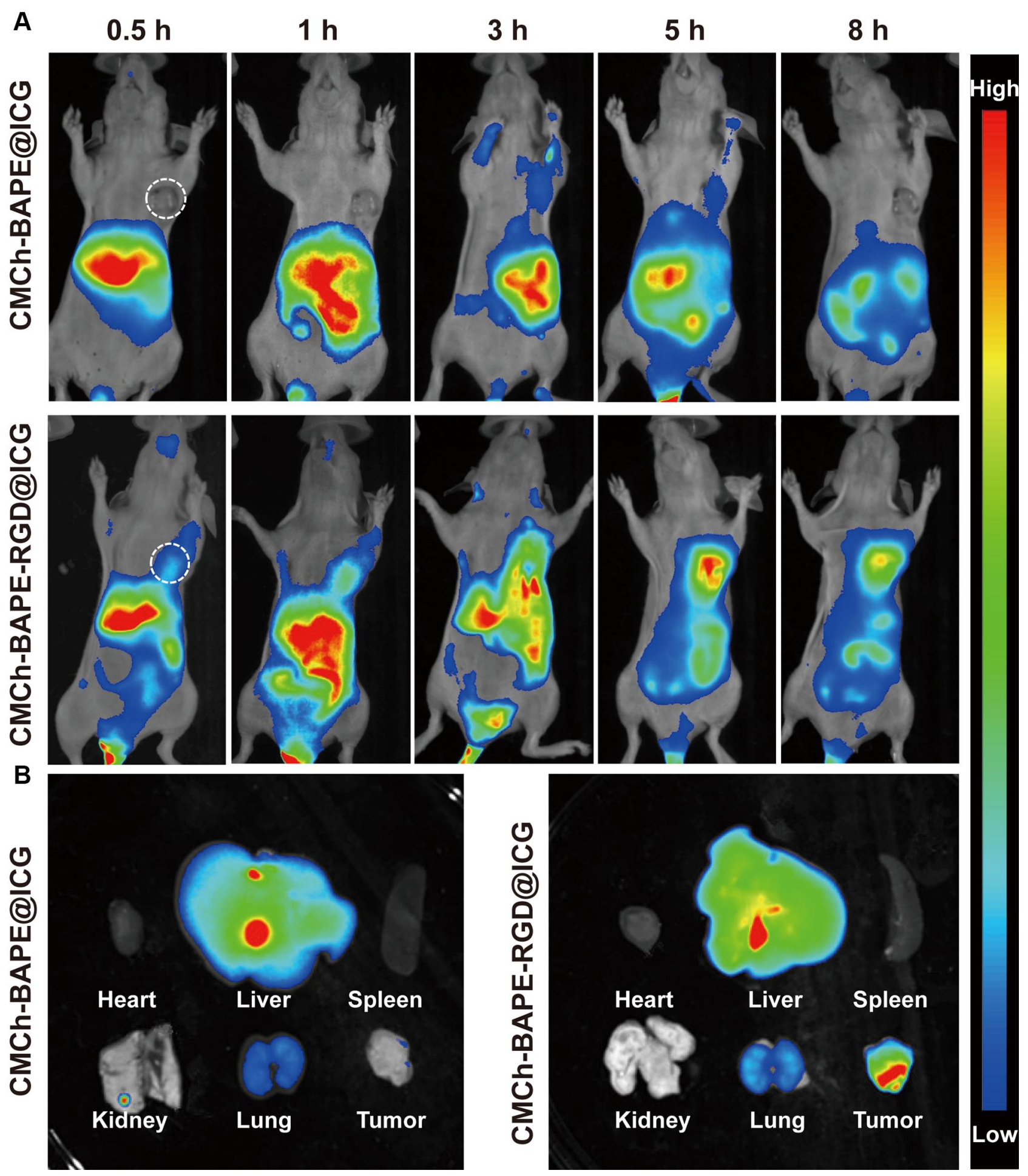

Figure 7 (A) In vivo fluorescent imaging of tumor-bearing mice after intravenous injection of CMCh-BAPE@ICG and CMCh-BAPE-RGD@ICG at indicated time points. (B) Ex vivo fluorescence signal of excised tumors and organs at $8 \mathrm{~h}$ after injection.

The issue about the entry of nanoparticles into solid tumors has been argued for several decades, the central concept of which is the EPR effect. However, the latest research reported that nanoparticles penetrate into several different tumor types mainly through transcytosis $(97 \%)$, and not via inter-endothelial gaps, while EPR effect contributed only a small part. ${ }^{31}$ How the tumor was instilled with nano-drugs may have one or 
A

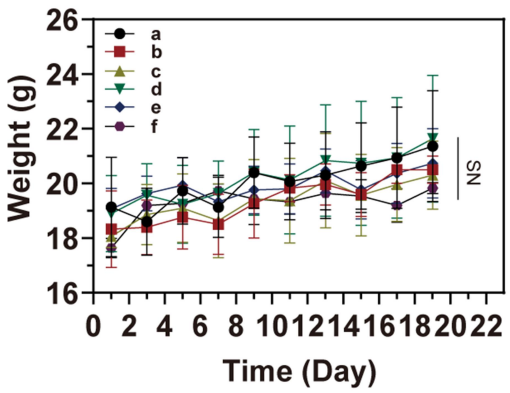

B

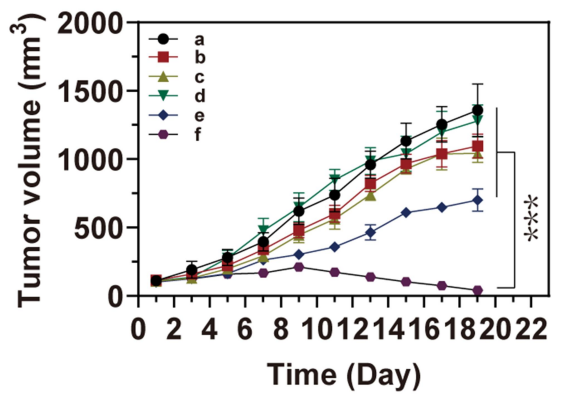

C

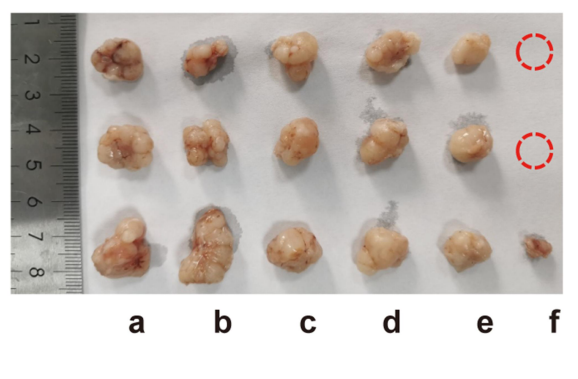

D

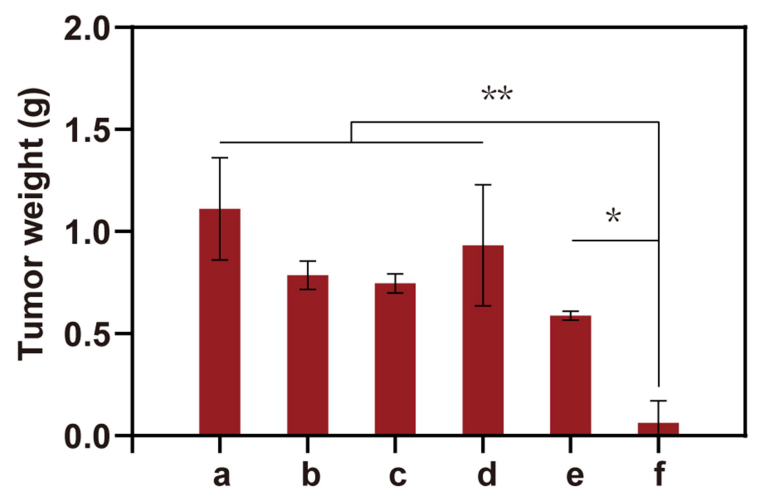

E

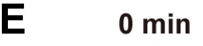

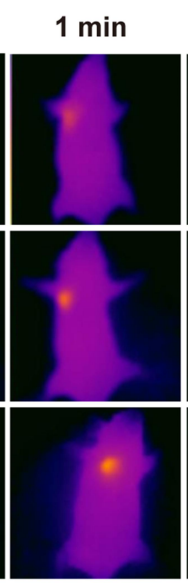

$3 \mathrm{~min}$

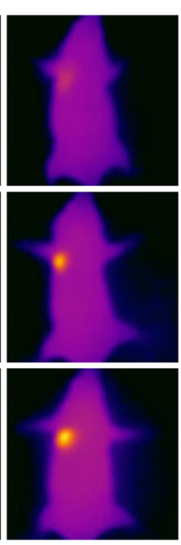

e
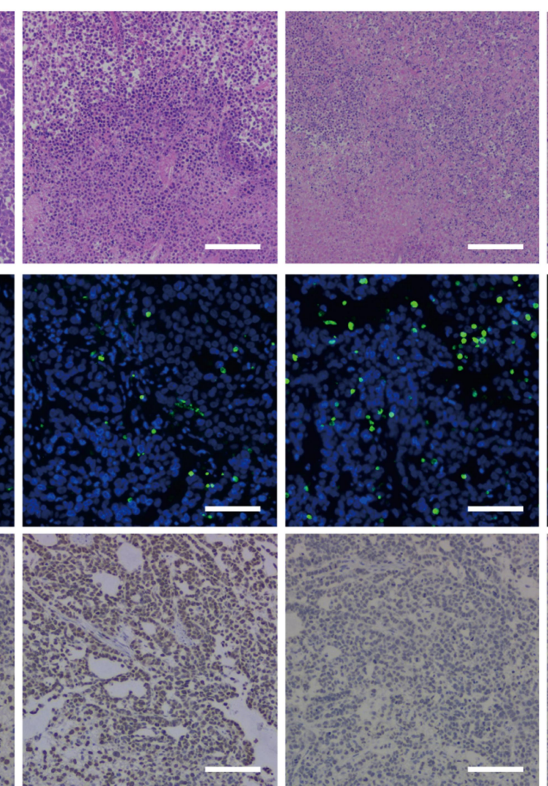

d

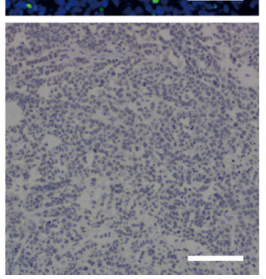

c
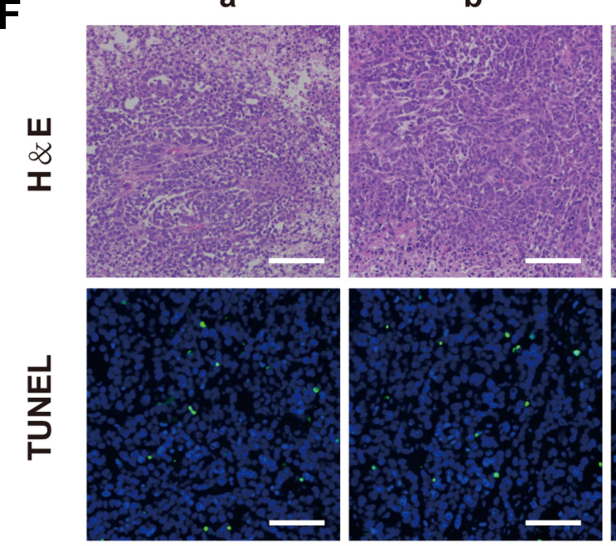
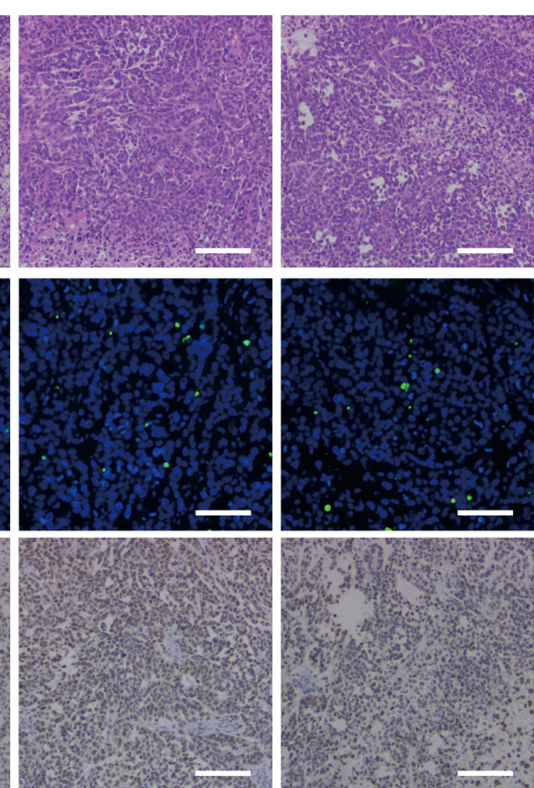

㩊

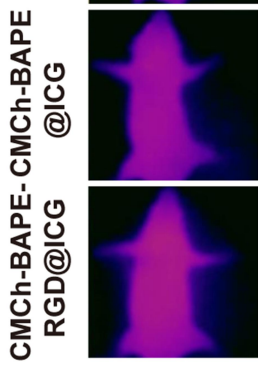

$5 \mathrm{~min}$

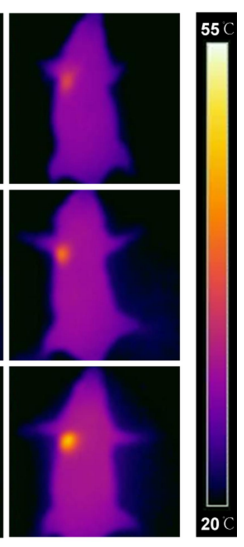

f
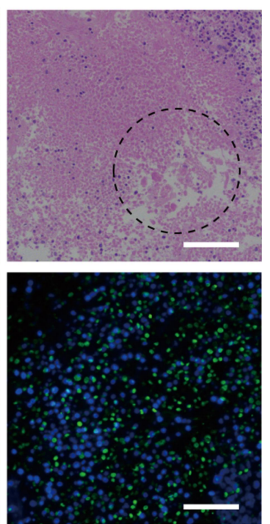

ํㅡㅁ

Figure 8 (A) Weight changes curve within 21-day treatments of each group. (B) Tumor growth curve within 2I-day treatments of each group. (C) Images of tumor in each group collected on day 2I. (D) Average tumor weight in each group after 21 -day treatment. (E) Infrared thermographic images of mice received different treatments. (F) H\&E, TUNEL and Ki67 staining of tumor sections in each group. Severely damaged tumor tissue are indicated by a black circle. Note that a-f represent different treatments: a.PBS, b.CMCh-BAPE@ICG, c.CMCh-BAPE-RGD@ICG, c.PBS+laser, d. CMCh-BAPE@ICG+laser, e. c.CMCh-BAPE-RGD@ICG +laser. (NS) P $\geq 0.05$. (*) P< 0.05, (**) P< 0.01 and $(* * *) P<0.001$.

more co-exist mechanisms, such as EPR effect, transcytosis, and perhaps other unknown mechanisms. There is no doubt that nano-drugs are beneficial in cancer treatment. In this study, we integrated NIR fluorescence imaging with photothermal therapy, where ICG served as both a fluorescent agent and a photosensitizer. When 
A

a

b

C

d

e

f
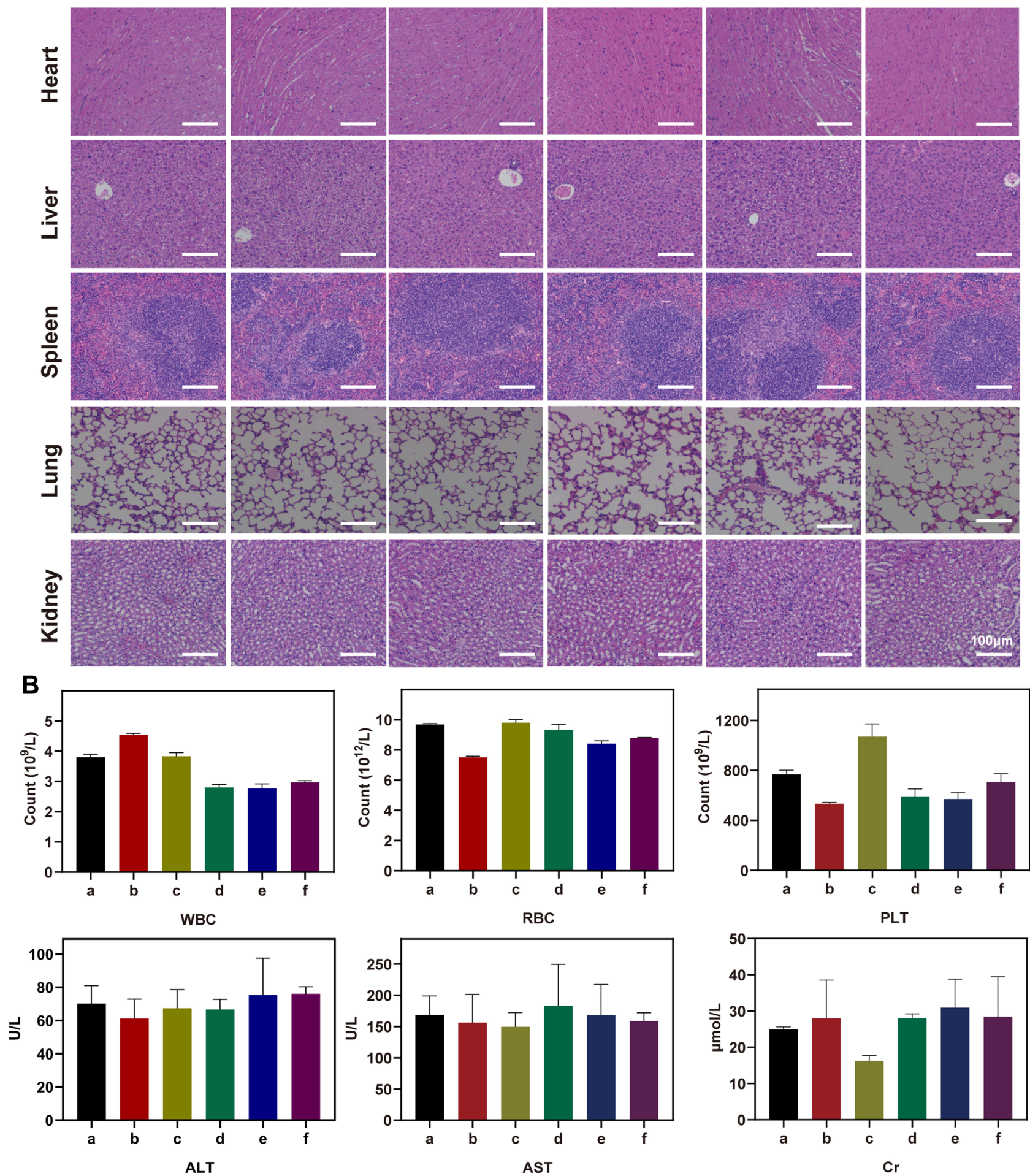

Figure 9 (A) H\&E staining images of mice organs after 2I-day treatment. (B) Blood parameters for evaluating effects on bone marrow hematopoietic system (RBC, WBC and platelet) and liver (ALT, AST) and kidney (Cr) function. Note that a-f represent the same treatments as Figure 8.

irradiated upon laser, the temperature could rise to $46.9^{\circ} \mathrm{C}$ rapidly and maintained relatively stable in vivo. It is reported that temperature over $42 \sim 45^{\circ} \mathrm{C}$ will lead to apoptotic and/or necrotic death. ${ }^{6-8,13}$ The underlying mechanism of hyperthermia-induced cell death may be that the rise in temperature will upregulate the apoptosis genes, activate caspase-3, suppress TNF- $\alpha$ resistance, and damage mitochondrial. ${ }^{49}$ 
As expected, CMCh-BAPE-RGD@ICG nanoparticles exhibited an excellent tumor ablation effect in vivo.

\section{In vivo Biosafety Evaluation}

Biosafety is an essential prerequisite for the clinical application of nanomaterials. Herein, the effects of different treatments on mice main organs and blood parameters were determined. The H\&E staining images in Figure 9A revealed no obvious injury on the tissue structure and morphology of the major organs in all groups. As demonstrated in Figure 9B, all groups displayed within the normal range in the levels of the blood indicators, including red blood cells (RBC), white blood cells (WBC), platelet (PLT), aspartate aminotransferase (AST), alanine aminotransferase (ALT) and creatinine $(\mathrm{Cr})$. These results confirmed the little influence on the hematopoietic (WBC, RBC, and PLT), liver (ALT and AST), and kidney (Cr) functions of each group. Therefore, CMCh-BAPE-RGD@ICG are promising nanoparticles with good biosafety for potential clinical applications.

\section{Conclusion}

In summary, we successfully synthesized a promising ROSresponsive RGD-modified nanoparticle, which could deliver ICG to gastric cancer for NIR imaging and PTT. ICG was coated in the core of nanoparticles as a near-infrared imaging agent and photosensitizer. RGD polypeptide was conjugated to the nanoparticles for promoting targeted accumulation and penetration in the tumor tissue. Boronic ester in BAPE made the particles hydrolyze in tumor the high ROS environment, resulting in more ICG release. These nanoparticles exhibited suitable size, improved aqueous stability, and excellent photothermal conversion efficiency. Moreover, flow cytometry and confocal microscopy confirmed the high-efficiency endocytosis in SGC7901 cells. Remarkably, the NIR fluorescence imaging could accurately demonstrate the location and margin of the tumor in tumor-bearing mice. The photothermal therapy of the targeted nanoparticle could efficiently ablate tumors by inducing necrosis and apoptosis in cancer cells. Additionally, hemocompatibility assessment in vitro and systematic toxicity evaluation in vivo displayed its good biocompatibility for potential clinical application. Collectively, the smart multifunctional nanoparticle provides a promising strategy for tumor-targeting NIR imaging and photothermal therapy.

\section{Abbreviations}

NIR, near-infrared; PTT, photothermal therapy; NDDS, nanoscale drug delivery systems; ICG, indocyanine green; EPR, enhanced permeability and retention; RME, receptor-mediated endocytosis; RGD, Arg-Gly-Asp peptide; ROS, reactive oxygen species; $\mathrm{CMCH}$, carboxymethyl chitosan; BAPE, benzeneboronic acid pinacol ester; EDC, 1-ethyl3-(3-dimethylaminopropyl) carbodiimide hydrochloride; NHS, N-hydroxysuccinimide; DOX, Doxorubicin; LE, loading efficiency; RBC, red blood cells; WBC, white blood cells; PLT, platelet; AST, aspartate aminotransferase; ALT, alanine aminotransferase; Cr, creatinine; $1 \mathrm{H}$ NMR, nuclear magnetic resonance spectroscopy; CLSM, confocal laser scanning microscope; TEM, transmission electron microscopy; DLS, dynamic light scattering; HE, hematoxylin-eosin CCK-8, cell counting kit-8.

\section{Ethical Approval and Consent to Participate}

All mice experiments were conducted following the guideline of the Ethics Committee of the Institutional Animal Care and Use Subcommittee of the Third Hospital of Sun Yat-sen University and the committee approved this study.

\section{Acknowledgments}

This work was supported in part by grants from Science and Technology Planning Project of Guangdong Province (2017B020227009 and 2019B030316011), by the National Natural Science Foundation of China (81472825), by the Outstanding Young Talents Support Program of the Third Affiliated Hospital of Sun Yat-sen University.

\section{Disclosure}

The authors report no conflicts of interest in this work.

\section{References}

1. Bray F, Ferlay J, Soerjomataram I, Siegel RL, Torre LA, Jemal A. Global cancer statistics 2018: GLOBOCAN estimates of incidence and mortality worldwide for 36 cancers in 185 countries. CA Cancer J Clin. 2018;68(6):394-424. doi:10.3322/caac.21492

2. Japanese Gastric Cancer A. Japanese gastric cancer treatment guidelines 2018 (5th edition). Gastric Cancer. 2020. doi:10.1007/s10120020-01042-y

3. Wang FH, Shen L, Li J, et al. The Chinese Society of Clinical Oncology (CSCO): clinical guidelines for the diagnosis and treatment of gastric cancer. Cancer Commun (Lond). 2019;39(1):10. doi:10.1186/s40880-019-0349-9 
4. Ajani JA, D'Amico TA, Almhanna K, et al. Gastric Cancer, Version 3.2016, NCCN Clinical Practice Guidelines in Oncology. $J$ Natl Compr Canc Netw. 2016;14(10):1286. doi:10.6004/jnccn.2016.0137

5. Zhang P, Zheng Z, Ling L, et al. w09, a novel autophagy enhancer, induces autophagy-dependent cell apoptosis via activation of the EGFR-mediated RAS-RAF1-MAP2K-MAPK1/3 pathway. Autophagy. 2017;13(7):1093-1112. doi:10.1080/15548627.2017.1319039

6. Peng J, Xiao Y, Li W, et al. Photosensitizer micelles together with IDO inhibitor enhance cancer photothermal therapy and immunotherapy. Adv Sci (Weinh). 2018;5(5):1700891. doi:10.1002/ advs.201700891

7. Wei W, Zhang X, Zhang S, Wei G, Su Z. Biomedical and bioactive engineered nanomaterials for targeted tumor photothermal therapy: a review. Mater Sci Eng C Mater Biol Appl. 2019;104:109891. doi:10.1016/j.msec.2019.109891

8. Chen J, Ning C, Zhou Z, et al. Nanomaterials as photothermal therapeutic agents. Prog Mater Sci. 2019;99:1-26. doi:10.1016/j. pmatsci.2018.07.005

9. Zhang F, Liu S, Zhang N, et al. X-ray-triggered NO-released Bi-SNO nanoparticles: all-in-one nano-radiosensitizer with photothermal/gas therapy for enhanced radiotherapy. Nanoscale. 2020. doi:10.1039/ d0nr04634e

10. Yang $\mathrm{G}, \mathrm{Xu} \mathrm{L}$, Chao $\mathrm{Y}$, et al. Hollow $\mathrm{MnO} 2$ as a tumor-microenvironment-responsive biodegradable nano-platform for combination therapy favoring antitumor immune responses. Nat Commun. 2017;8(1):902. doi:10.1038/s41467-017-01050-0

11. Wu J, Williams GR, Niu S, Gao F, Tang R, Zhu LM. A multifunctional biodegradable nanocomposite for cancer theranostics. Adv Sci (Weinh). 2019;6(14):1802001. doi:10.1002/ advs.201802001

12. Yu B, Choi B, Li W, Kim DH. Magnetic field boosted ferroptosis-like cell death and responsive MRI using hybrid vesicles for cancer immunotherapy. Nat Commun. 2020;11(1):3637. doi:10.1038/ s41467-020-17380-5

13. Guo L, Niu G, Zheng X, et al. Single near-infrared emissive polymer nanoparticles as versatile phototheranostics. Adv Sci (Weinh). 2017;4 (10):1700085. doi:10.1002/advs.201700085

14. Yan F, Wu H, Liu H, et al. Molecular imaging-guided photothermal/ photodynamic therapy against tumor by iRGD-modified indocyanine green nanoparticles. $J$ Control Release. 2016;224:217-228. doi:10.1016/j.jconrel.2015.12.050

15. Kim M, Lee JH, Nam JM. Plasmonic photothermal nanoparticles for biomedical applications. Adv Sci (Weinh). 2019;6(17):1900471. doi:10.1002/advs.201900471

16. Lu L, Li B, Ding S, et al. NIR-II bioluminescence for in vivo high contrast imaging and in situ ATP-mediated metastases tracing. Nat Commun. 2020;11(1):4192. doi:10.1038/s41467-020-18051-1

17. Savchuk OA, Carvajal JJ, Cesteros Y, et al. Mapping temperature distribution generated by photothermal conversion in graphene film using Er, Yb: naYF4Nanoparticles prepared by microwave-assisted solvothermal method. Front Chem. 2019;7:88. doi:10.3389/ fchem.2019.00088

18. Yang Z, Cheng R, Zhao C, et al. Thermo- and pH-dual responsive polymeric micelles with upper critical solution temperature behavior for photoacoustic imaging-guided synergistic chemo-photothermal therapy against subcutaneous and metastatic breast tumors. Theranostics. 2018;8(15):4097-4115. doi:10.7150/thno.26195

19. Yan L, Qiu L. Indocyanine green targeted micelles with improved stability for near-infrared image-guided photothermal tumor therapy. Nanomedicine. 2015;10(3):361-373. doi:10.2217/nnm.14.118

20. Qin L, Cao J, Shao K, Tong F, Yang Z. A tumor-to-lymph procedure navigated versatile gel system for combinatorial therapy against tumor recurrence and metastasis. Sci Adv. 2020;6(36):eabb3116. doi:10.1126/sciadv.abb3116
21. Liu R, Hu C, Yang Y, Zhang J, Gao H. Theranostic nanoparticles with tumor-specific enzyme-triggered size reduction and drug release to perform photothermal therapy for breast cancer treatment. Acta Pharm Sin B. 2019;9(2):410-420. doi:10.1016/j.apsb.2018.09.001

22. Schwarz C, Plass I, Fitschek F, et al. The value of indocyanine green clearance assessment to predict postoperative liver dysfunction in patients undergoing liver resection. Sci Rep. 2019;9(1):8421. doi:10.1038/s41598-019-44815-x

23. Hwang Y, Yoon $\mathrm{H}$, Choe $\mathrm{K}$, et al. In vivo cellular-level real-time pharmacokinetic imaging of free-form and liposomal indocyanine green in liver. Biomed Opt Express. 2017;8(10):4706-4716. doi:10.1364/BOE.8.004706

24. Lee KM, Kim JM, Lee EJ, Kim TW. Anterior optic nerve head perfusion is dependent on adjacent parapapillary choroidal perfusion. Sci Rep. 2019;9(1):10999. doi:10.1038/s41598-01947534-5

25. Asanuma D, Kobayashi H, Nagano T, Urano Y. Fluorescence imaging of tumors with "smart" pH-activatable targeted probes. Methods Mol Biol. 2009;574:47-62. doi:10.1007/978-1-60327-321-3_5

26. Wang Z, Ju Y, Ali Z, et al. Near-infrared light and tumor microenvironment dual responsive size-switchable nanocapsules for multimodal tumor theranostics. Nat Commun. 2019;10(1):4418. doi:10.1038/ s41467-019-12142-4

27. Kim T, Park J, Kim TI. Cholic acid-conjugated methylcellulose-polyethylenimine nano-aggregates for drug delivery systems. Nanomaterials (Basel). 2019;9(3):459. doi:10.3390/ nano9030459

28. Xu M, Zhang $\mathrm{C}$, Wu J, et al. PEG-detachable polymeric micelles self-assembled from amphiphilic copolymers for tumor-acidity-triggered drug delivery and controlled release. ACS Appl Mater Interfaces. 2019;11(6):5701-5713. doi:10.1021/acsami.8b13059

29. Li Y, Zhai Y, Liu W, et al. Ultrasmall nanostructured drug based $\mathrm{pH}$-sensitive liposome for effective treatment of drug-resistant tumor. J Nanobiotechnology. 2019;17(1):117. doi:10.1186/s12951-019-0550-7

30. Oh JY, Kim HS, Palanikumar L, et al. Cloaking nanoparticles with protein corona shield for targeted drug delivery. Nat Commun. 2018;9 (1):4548. doi:10.1038/s41467-018-06979-4

31. Sindhwani S, Syed AM, Ngai J, et al. The entry of nanoparticles into solid tumours. Nat Mater. 2020;19(5):566-575. doi:10.1038/s41563019-0566-2

32. Liu R, Xiao W, Hu C, Xie R, Gao H. Theranostic size-reducible and no donor conjugated gold nanocluster fabricated hyaluronic acid nanoparticle with optimal size for combinational treatment of breast cancer and lung metastasis. J Control Release. 2018;278:127-139. doi:10.1016/j.jconrel.2018.04.005

33. Sun Y, Zhao Y, Teng S, et al. Folic acid receptor-targeted human serum albumin nanoparticle formulation of cabazitaxel for tumor therapy. Int $J$ Nanomedicine. 2019;14:135-148. doi:10.2147/IJN. S181296

34. Nieberler M, Reuning U, Reichart F, et al. Exploring the role of RGD-recognizing integrins in cancer. Cancers (Basel). 2017;9(9). doi:10.3390/cancers9090116

35. Raab-Westphal S, Marshall JF, Goodman SL. Integrins as therapeutic targets: successes and cancers. Cancers (Basel). 2017;9(9). doi:10.3390/cancers 9090110

36. Boger C, Warneke VS, Behrens HM, et al. Integrins alphavbeta3 and alphavbeta5 as prognostic, diagnostic, and therapeutic targets in gastric cancer. Gastric Cancer. 2015;18(4):784-795. doi:10.1007/ s10120-014-0435-2

37. Garcia Ribeiro RS, Belderbos S, Danhier P, et al. Targeting tumor cells and neovascularization using RGD-functionalized magnetoliposomes. Int $J$ Nanomedicine. 2019;14:5911-5924. doi:10.2147/IJN.S214041 
38. Shan W, Chen R, Zhang Q, et al. Improved stable Indocyanine Green (ICG)-mediated cancer optotheranostics with naturalized hepatitis B core particles. Adv Mater. 2018;30(28):e1707567. doi:10.1002/ adma.201707567

39. Xu C, Song R, Lu P, et al. A pH-responsive charge-reversal drug delivery system with tumor-specific drug release and ROS generation for cancer therapy. Int J Nanomedicine. 2020;15:65-80. doi:10.2147/ IJN.S230237

40. Tang L, Yang Z, Zhou Z, et al. A logic-gated modular nanovesicle enables programmable drug release for on-demand chemotherapy. Theranostics. 2019;9(5):1358-1368. doi:10.7150/thno.32106

41. Qu C, Li J, Zhou Y, et al. Targeted delivery of doxorubicin via CD147-mediated $\mathrm{ROS} / \mathrm{pH}$ dual-sensitive nanomicelles for the efficient therapy of hepatocellular carcinoma. AAPS J. 2018;20(2):34. doi:10.1208/s12248-018-0195-8

42. Gao J, Zhong W, He J, et al. Tumor-targeted PE38KDEL delivery via PEGylated anti-HER2 immunoliposomes. Int J Pharm. 2009;374(1-2):145-152. doi:10.1016/j.ijpharm.2009.03.018

43. Wang Y, Xie Y, Li J, et al. Tumor-penetrating nanoparticles for enhanced anticancer activity of combined photodynamic and hypoxia-activated therapy. ACS Nano. 2017;11(2):2227-2238. doi:10.1021/acsnano.6b08731

44. Kirchherr AK, Briel A, MaDer K. Stabilization of indocyanine green by encapsulation within micellar systems. Mol Pharm. 2009;6 (2):480. doi:10.1021/mp8001649
45. Fang L, Zhang W, Wang Z, et al. Novel mitochondrial targeting charge-reversal polysaccharide hybrid shell/core nanoparticles for prolonged systemic circulation and antitumor drug delivery. Drug Deliv. 2019;26(1):1125-1139. doi:10.1080/10717544.2019.1687614

46. Sankar R, Ravikumar V. Biocompatibility and biodistribution of suberoylanilide hydroxamic acid loaded poly (DL-lactide-co-glycolide) nanoparticles for targeted drug delivery in cancer. Biomed Pharmacother 2014;68(7):865-871 doi: $10.1016 / \mathrm{j}$ biopha.2014.07.015

47. Yu MZ, Pang WH, Yang T, et al. Systemic delivery of siRNA by T7 peptide modified core-shell nanoparticles for targeted therapy of breast cancer. Eur J Pharm Sci. 2016;92:39-48. doi:10.1016/j. ejps.2016.06.020

48. Gref R, Domb A, Quellec P, et al. The controlled intravenous delivery of drugs using PEG-coated sterically stabilized nanospheres. $A d v$ Drug Deliv Rev. 2012;64(supp_S):316-326. doi:10.1016/j. addr.2012.09.008

49. Chu KF, Dupuy DE. Thermal ablation of tumours: biological mechanisms and advances in therapy. Nat Rev Cancer. 2014;14(3):199-208. doi:10.1038/nrc3672
International Journal of Nanomedicine

\section{Publish your work in this journal}

The International Journal of Nanomedicine is an international, peerreviewed journal focusing on the application of nanotechnology in diagnostics, therapeutics, and drug delivery systems throughout the biomedical field. This journal is indexed on PubMed Central, MedLine, CAS, SciSearch ${ }^{\mathbb{}}$, Current Contents ${ }^{\mathbb{R}} /$ Clinical Medicine,

\section{Dovepress}

Journal Citation Reports/Science Edition, EMBase, Scopus and the Elsevier Bibliographic databases. The manuscript management system is completely online and includes a very quick and fair peer-review system, which is all easy to use. Visit http://www.dovepress.com/ testimonials.php to read real quotes from published authors. 